This is a postprint version of the following published document:

A. Gómez-García, J. Sánchez-Prieto, A. Soria-Verdugo, D. Santana (2014). Moving bed. syngas conditioning: Modelling, in Applied Thermal Engineering, Volume: 62, Issue: 2, Pages 809-822. Doi:10.1016/j.applthermaleng.2013.10.010.

(C) 2013 Elsevier

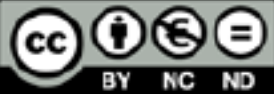

This work is licensed under a Creative Commons Attribution-NonCommercialNoDerivatives 4.0 International License. 


\title{
Moving bed syngas conditioning: Modelling
}

\author{
Alberto Gómez-García*, Javier Sánchez-Prieto, Antonio Soria-Verdugo, Domingo Santana Thermal and Fluid \\ Engineering Department, University of Carlos III, Avda. de la Universidad, 30, Leganés, 28911 Madrid, Spain
}

\begin{abstract}
This paper presents a modelling approach for simulating tars and particulate (dust) removal in a moving bed heat exchange filter (MBHEF) in order to satisfy gas requirements of end-use syngas applications: engines and turbines. The two-dimension, adiabatic, steady-state proposed model accounts for two-phase (gas and solid) and neglects conduction and mass diffusion. Tars condensation is modelled through representative tar class lumps: phenol (class 2), naphthalene (class 4), pyrene (class 5). The model also considers tar concentration influence on the tar dew point. The filtration model is taken from literature. A sensitivity analysis is performed varying the particle size and the superficial gas velocity. Maps of temperature and tars abatement efficiency are presented. The simulation results indicate the feasibility of the use a MBHEF as tars removal equipment benefiting its advantages against others gas-cleaning methods with acceptable pollutant removal efficiencies, ranging $88-94 \%$ for ranges studied. Results also point out low gas velocities $(0.5-1 \mathrm{~m} / \mathrm{s})$ and high particle size $(400-700 \mu \mathrm{m})$ for reducing operational costs in MBHEFs with compact size.
\end{abstract}

Keywords: Tar removal, Biomass gasification, Syngas cleaning-up, Moving bed, Heat exchange.

\section{Introduction}

From some time past, there is an increasing concern about global warming and its effects due to Green House Gas (GHG) emissions of anthropologic origin since fossil fuels are still the dominant source of global primary energy supply [1]. Then, much effort has been addressed in research and development of less polluting fuel-to-energy processes such biomass conversion technologies [2], sustainable renewable energy systems such as solarbased, ground source-based and day-lighting [3] and solar en-ergy, wind energy and bioenergy [4], methods and tools to evaluate the availability of renewable energy sources [5] and investigation of $\mathrm{CO}_{2}$ capture and storage techniques [6,7]. Additionally, in the present days, there seems still to be a long way to improve the efficiency of every step in power production process.

\footnotetext{
* Corresponding author. Tel.: +34916246032.

E-mail address: algomez@ing.uc3m.es (A. Gómez-García).
}

In the way to improve process efficiency and lower pollutant emissions many attention is focused on biomass gasification (BG). The interest in biomass as fuel mainly lays in the very low net GHG emissions compared to others fuels when it is processed by some thermal technology conversion [8]. Among all existing conversion routes, biomass gasification in fluidized beds (BGFB's) has been proven as a feasible and eco-friendly fuel-to-energy thermal conversion method [2]. However, this type of fuel conversion presents several drawbacks. One of the most important disadvantages of BGFB's is the unacceptable tar content in the raw syngas for power production in internal combustion engines, combined cycle gas turbine, fuel cells, chemical synthesis, etc [9]. The tar problem in BG underlie in its physical properties: a low dew point yielding the condensation of sticky and refractory slurries that can lead to operational problems as blockage and attrition in filters, heat exchangers, exit pipes, etc [10]. Thus, tar removal is key for a successful application of biomass-derived producer gas though is still a challenge that has to be solved [11].

Gas cleaning systems for conditioning syngas produced by BG reactors have been extensively studied and reviewed along the 
time since gas quality requirements for different gas application changes with the technology development and improvement [9]. As for example, the NREL of Colorado [9] and the ECN Institution [12] have reviewed the state-of-the-art of tar removal technologies. The current work proposes the use of a Moving Bed Heat Exchanger Filter (MBHEF) as hot gas clean-up system for removing tar and particulate material. The choice of a MBHEF as hot gas cleaning equipment is justified by: the possibility of operating at high temperatures (up to $700-800^{\circ} \mathrm{C}$, the exhaust gas temperature from the gasifier) in contrast to problems presented by others devices such as ceramic filters over $400{ }^{\circ} \mathrm{C}$ [13], noclogging and non-pressure increase during operation [14]. All these advantages offered by the MBHEF system would avoid shut-down and its associated costs in comparison with traditional hot gas clean-up devices.

To date, MBHEF's have been studied because of offering particular advantages when cleaning hot gas exhaust from reactors such BFBG's in contrast to traditional equipment: ceramic filters, scrubbers, electrostatic precipitators or bag filters in order to remove particulate material. This paper is aimed at evaluating the use of a MBHEF for conditioning syngas from BG processes in order to give a usable gas for power production applications. The purpose of the model proposed is to provide a predictive tool for simulating such steady MBHEF operation and to give tars and particles reduction level maps. The MBHEF will be optimised [15] in order to improve the tars and particulate removal efficiency $\left(\eta_{\text {tars }}\right.$ and $\eta_{\text {dust }}$ respectively) as well as the heat transfer and pressure drop.

Finally, concerning the particulate removal, the optimisation of MBHEF study focuses on the tar removal point of view since very high particle collection efficiencies can be easily achieved in comparison to tar reduction levels [16].

\subsection{Gas quality requirements}

The performance, investment and operational costs of a hot gas cleaning system depend on the syngas quality demanded and the reactor performance whereas the quality of the gas produced is determined by the end-use of the gas. The need of tar and particulate removal depends basically on the syngas application. For instance, the acceptable limit of tar concentration in a syngas for engine applications varies according to the author [9]. In this study, the limits adopted were those proposed by Refs. $[9,17,18]$ (Table 1 ). The tars nature, but not the tars concentration, is key for successful assessment of the suitability of syngas end-use as GómezBarea and Leckner [19] reported, since it has been demonstrated that gas containing $100 \mathrm{mg} / \mathrm{Nm}^{3}$ of tars with a dew point of $70{ }^{\circ} \mathrm{C}$ causes mechanical problems in engines but a gas with $5000 \mathrm{mg} /$ $\mathrm{Nm}^{3}$ of tars and a dew point of $20^{\circ} \mathrm{C}$ has been used without engines problems. Here, for the sake of simplicity, the tar removal analysis is conducted from a concentration point of view, not exclusively focused on the tar nature. Furthermore, gas derived from biomass and wastes contain others pollutant species such as sulphur compounds, alkaline metals and dust. All these contaminants can be removed by means of conventional devices downstream of the gasifier before condensing tars. Thus, tar conversion is of interest

Table 1

Fuel requirements for internal combustion engines and gas turbines $[9,17,18]$.

\begin{tabular}{llc}
\hline Contaminant & Allowable concentration & \\
\cline { 2 - 3 } & IC engine & Gas turbine \\
\hline $\operatorname{Tar}\left(\mathrm{mg} / \mathrm{Nm}^{3}\right)$ & $<50$ & $<5$ \\
Particles $\left(\mathrm{mg} / \mathrm{Nm}^{3}\right)$ & $<50$ & $<30$ \\
Particle size $(\mu \mathrm{m})$ & $<10$ & $<5$ \\
\hline
\end{tabular}

since it increases the heating value of syngas. For instance, the low heating value (LHV) of tars is estimated to be around $26-40 \mathrm{MJ} / \mathrm{kg}$ [20].

\section{Tar removal methods review}

To accomplish the objectives of tar removal, tars behaviour in reactors should be understood. This involves knowing tars nature and its formation mechanisms (out of the scope of this paper). As follows, tar removal technologies are briefly presented, pointing out their main strong and weak points. Finally, the MBHEF is chosen as technology solution for tar elimination in order to give syngas with tars content levels acceptable for end-use applications: gas turbines (GT's) and internal combustion engines (ICE's).

\subsection{Tar definition}

Milne and Evans [9] and Li and Suzuki [10] have reviewed tars issues related to cracking, removal, definition and its characterization. Tars or tar fraction in biomass, representing up to half of primary pyrolysis products from devolatilization, is a very complex mixture of chemical species with a heavier molecular weight than permanent gases and the so-called $C_{2}$ and $C_{3}$ fraction. Tars comprise a broad range of chemical species tending to be refractory and difficult of being removed by means of thermal, catalytic and physical processes. This fraction of condensable hydrocarbons includes from single ring compounds as benzene to 5-ring aromatic compounds with others oxygenated compounds and polycyclic aromatic hydrocarbons (PAH).

The importance of tar class concentration and even tar lumping when estimating the temperature at which tars condensation can take place has been recently evidenced [21]. Tars behaviour has a great impact in the right design of devices managing gases with non-negligible tar content. Thus, this property is a useful and valuable parameter to design tar removal equipment and choose operating conditions of reactors for producing syngas.

\subsection{Tar removal methods}

The tar removal technologies can be sort out in two categories: primary and secondary methods depending on the location in the BGFB process where tars are removed [22].

Primary methods are addressed to prevent or convert tar formed inside the gasifier so that these types of technologies would save the use of secondary methods downstream. Three types of measures can be taken as primary methods: the proper design of reactor [11], the right selection of operating: use and location of secondary air, equivalence ratio and biomass moisture [23]; steam and $\mathrm{N}_{2}$ (pyrolysis) as gasifying agents [24]; co-gasification of high moisture woodchips and shredded rubber waste [25] and the use of proper bed additives/catalysts during gasification: silica sand, calcined limestone, combination of calcined limestone and calcined waste [24]; inert quartzite, olivine, dolomite, Ni-alumina [26]; silica sand, alumina, alumina impregnated with nickel [27].

On the other hand, secondary methods are aimed to treat the hot gas after the gasifier. They consist of chemical or physical treatment: thermal or catalytic cracking and mechanical methods such as use of electrostatic filters, ceramic filters, fabric filters, scrubbers and rotating particle separators.

In spite of the existence of a wide variety of tar removal technologies, not all of them are suitable from an economic point of view. Although secondary methods have been proven and shown as efficient, new trends address to the investigation of primary methods. In fact, recent works are focused on the development and the optimisation of primary tar technologies. These works 


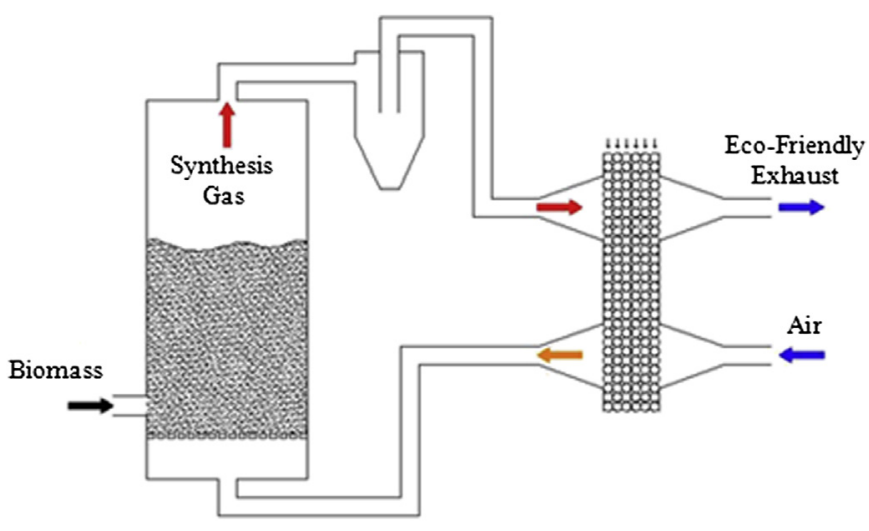

Fig. 1. MBHEF syngas conditioning coupled to a BFBG reactor.

investigate the effect of metal-based and non-metallic catalysts in tar removal efficiency in BFBG: inert quartzite, olivine, dolomite and $\mathrm{Ni}$-alumina [26]; $\mathrm{CaO}, \mathrm{SiO}_{2}, \mathrm{~A}_{2} \mathrm{O}_{3}, \mathrm{CuMn}$ and NiMn [28]; sand and olivine [29]; Mo/V/W-mixed oxides [30].

According to the review of Devi et al. [22], there are some re-marks about the use of active bed material in BG processes:

- A change in product gas composition.

- An increase of $\mathrm{H}_{2}$ content.

- A slight decrease of $\mathrm{CO}$ and an increase of $\mathrm{CO}_{2}$ content.

- Almost no variation of $\mathrm{CH}_{4}$.

- Dependence of catalytic activity on gasification conditions.

- Severe problems related to catalyst deactivation and carryover of fines.

Additionally, the use of primary methods involves design modifications in reactors and/or changes in operating conditions in order to keep the quality and composition of the producer gas. Obviously, these syngas properties are desired to be constants when tar removal technologies are applied for satisfying quality syngas demand from markets. In the current paper, a cross-flow MBHEF device as secondary method is proposed to reduce tar levels in syngas saving costs derived from reactor design modifications or the use of additives/catalysts.

MBHEF systems could be employed as a tar removal device. The cross-flow MBHEF concept for tar and particulate removal would provide a high contact area between gas and solids without either entrainment or elutriation of solids. Furthermore, to date, MBHEF systems have only been designed for heat transfer and hot gas particulate removal: to be optimised from an energy and exergy point of view [15]; to propose a modelling approach to predict dust filtration with the gas temperature and the dust particle diameter [31] or with the solid velocity [32]; to be improved by the analysis of their design, strong features and drawbacks and to point out their performance according to a patent review [33]; to study the feasibility of using Lapilli as granular medium [34]. Dealing with BFBG reactors, MBHEF systems could also act as a preheater of the gasifying agent as the exhaust gas is cooled down and conditioned to be used for power production in ICE's, GT's, etc (Fig. 1). Finally, all these properties would yield compact equipment with high gas cleaning efficiency and saving costs.

\section{Model description}

The analysis of the MBHEF operation is based on the coupled models of heat exchange, mass transfer and filtration of all species. Once the heat and mass transfer mechanisms for tars removal is presented, the filtration mechanism for particulate collection is described.

\subsection{MBHE model}

The MBHEF device is featured by the cross-flow of a gas stream and a down-moving solid stream. When the gas is cool down by the particles, the condensable material (tars) would be removed from the gas flow into the solid mass flow, collected at the bottom part of the equipment. The gas inlet with condensable material enters the device and leaves it free of tars or with low tar content. Meanwhile, the liquid and solid phases act as interphase where condensation can take place yielding liquid film around particle surface.

Fig. 2 represents a micro-scale zoom of the fixed bed and briefly describes heat and mass transfer between all phases: gas, liquid and solid and the direction of mass and energy flow. The heat and mass transfer processes are all coupled and take place between each pair of phases. The nomenclature used in defining the governing equations denotes the couple of these processes in this way. Note that Fig. 2 addresses to the general case for removal of substance when its concentration is appreciable.

The energy and mass conservation equations can be applied to a typical MBHEF system. Fig. 3 is a schematic sketch of energy and mass flows inside the MBHEF in an arbitrary control volume, representing the characteristics parameters (temperature, mass flows and substances concentration) for both gas and solid phases. The gas phase transfers mass in form of liquid phase which stays around the surface particle in the solid phase. The condensation rate would be related to the mass flux difference between two consecutive control volumes along one direction.

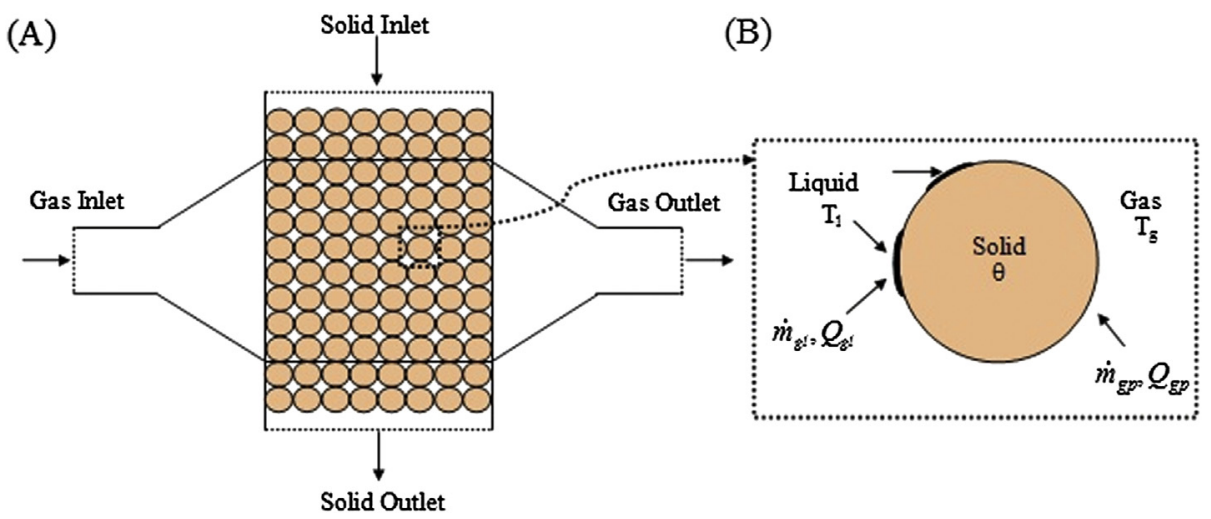

Fig. 2. Schematic of a MBHE: for a general case with non-negligible phase condensable (A), and heat and mass transfer between all phases involved at particle-scale (B). 


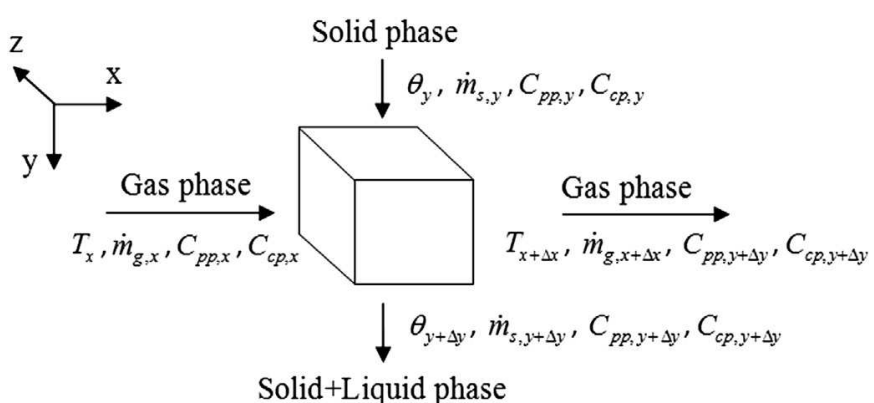

Fig. 3. Mass balance in an arbitrary control volume inside the MBHEF.

Generally, dealing with condensable species in fixed or fluidized beds means three phase systems. Assuming plug flow for gas, liquid and solid phases in cartesian coordinates, the energy and mass conservation equations in the general form can be written as $\mathrm{Hu}$ et al. [35] propose:

Gas phase energy equation

$$
\begin{aligned}
\varepsilon_{\mathrm{g}} & \rho_{\mathrm{g}} c_{\mathrm{pg}}\left(\frac{\partial T_{\mathrm{g}}}{\partial t}+u_{\mathrm{g}} \frac{\partial T_{\mathrm{g}}}{\partial x}+v_{\mathrm{g}} \frac{\partial T_{\mathrm{g}}}{\partial y}+w_{\mathrm{g}} \frac{\partial T_{\mathrm{g}}}{\partial z}\right) \\
= & k_{\mathrm{gx}} \frac{\partial^{2} T_{\mathrm{g}}}{\partial x^{2}}+k_{\mathrm{gy}} \frac{\partial^{2} T_{\mathrm{g}}}{\partial y^{2}}+k_{\mathrm{gz}} \frac{\partial^{2} T_{\mathrm{g}}}{\partial z^{2}}+h_{\mathrm{gp}} a_{\mathrm{gp}}\left(\theta-T_{\mathrm{g}}\right) \\
& +h_{\mathrm{gl}} a_{\mathrm{gl}}\left(T_{\mathrm{l}}-T_{\mathrm{g}}\right)-U_{\mathrm{gw}} a_{\mathrm{gw}}\left(T_{\mathrm{g}}-T_{\infty}\right)+q_{\mathrm{rad}} \\
& \left.-\sum_{c}^{n} \dot{m}_{\mathrm{gp}, c}+\sum_{c}^{n} \dot{m}_{\mathrm{gl}, c}\right) h_{\mathrm{fg}, c}+\sum_{r}^{n r} G_{\mathrm{g}, c} \Delta H_{\mathrm{r}}
\end{aligned}
$$

Liquid phase energy equation

$$
\begin{aligned}
\varepsilon_{\mathrm{l}} \rho_{\mathrm{l}} c_{\mathrm{pl}} & \left(\frac{\partial T_{\mathrm{l}}}{\partial t}+u_{\mathrm{l}} \frac{\partial T_{1}}{\partial x}+v_{\mathrm{l}} \frac{\partial T_{\mathrm{l}}}{\partial y}+w_{\mathrm{l}} \frac{\partial T_{\mathrm{l}}}{\partial z}\right) \\
= & k_{\mathrm{lx}} \frac{\partial^{2} T_{\mathrm{l}}}{\partial x^{2}}+k_{\mathrm{ly}} \frac{\partial^{2} T_{1}}{\partial y^{2}}+k_{\mathrm{lz}} \frac{\partial^{2} T_{1}}{\partial z^{2}}+h_{\mathrm{lp}} a_{\mathrm{lp}}\left(\theta-T_{\mathrm{l}}\right)+h_{\mathrm{gl}} a_{\mathrm{gl}}\left(T_{\mathrm{g}}-T_{\mathrm{l}}\right) \\
& -U_{\mathrm{lw}} a_{\mathrm{lw}}\left(T_{1}-T_{\infty}\right)+q_{\mathrm{rad}}+\sum_{c}^{n} \dot{m}_{\mathrm{gl}, c} h_{\mathrm{fg}, c}+\sum_{r}^{n r} G_{\mathrm{l}, c} \Delta H_{r}
\end{aligned}
$$

Solid phase energy equation

$$
\begin{aligned}
\varepsilon_{\mathrm{p}} \rho_{\mathrm{p}} c_{\mathrm{pp}}\left(\frac{\partial \theta}{\partial t}+u_{\mathrm{p}} \frac{\partial \theta}{\partial x}+v_{\mathrm{p}} \frac{\partial \theta}{\partial y}+w_{\mathrm{p}} \frac{\partial \theta}{\partial z}\right) \\
=k_{\mathrm{px}} \frac{\partial^{2} \theta}{\partial x^{2}}+k_{\mathrm{py}} \frac{\partial^{2} \theta}{\partial y^{2}}+k_{\mathrm{pz}} \frac{\partial^{2} \theta}{\partial z^{2}}+h_{\mathrm{gp}} a_{\mathrm{gp}}\left(T_{\mathrm{g}}-\theta\right)+h_{\mathrm{lp}} a_{\mathrm{lp}}\left(T_{1}-\theta\right) \\
-U_{\mathrm{pw}} a_{\mathrm{pw}}\left(\theta-T_{\infty}\right)+q_{\mathrm{rad}}+\sum_{c}^{n} \dot{m}_{\mathrm{gp}, c} h_{\mathrm{fg}, c}+\sum_{r}^{n r} G_{\mathrm{p}, c} \Delta H_{r}
\end{aligned}
$$

Gas phase mass equation for condensable species

$$
\begin{aligned}
& \left(\frac{\partial}{\partial t}\left(\varepsilon_{\mathrm{g}} C_{\mathrm{c}}\right)+u_{\mathrm{f}} \frac{\partial C_{\mathrm{c}}}{\partial x}+v_{\mathrm{f}} \frac{\partial C_{\mathrm{c}}}{\partial y}+w_{\mathrm{f}} \frac{\partial C_{\mathrm{c}}}{\partial z}\right) \\
& \left.\quad=D_{\mathrm{c}} \frac{\partial^{2} C_{\mathrm{c}}}{\partial x^{2}}+\frac{\partial^{2} C_{\mathrm{c}}}{\partial y^{2}}+\frac{\partial^{2} C_{\mathrm{c}}}{\partial z^{2}}\right)+G_{\mathrm{g}, \mathrm{c}}-\sum_{c}^{n} \dot{m}_{\mathrm{gp}, c}-\sum_{c}^{n} \dot{m}_{\mathrm{gl}, c}
\end{aligned}
$$

Solid phase mass equation for condensable species

$$
\begin{aligned}
& \left(\frac{\partial}{\partial t}\left(\varepsilon_{\mathrm{p}} C_{\mathrm{c}, \mathrm{p}}\right)+u_{\mathrm{p}} \frac{\partial C_{\mathrm{c}, \mathrm{p}}}{\partial x}+v_{\mathrm{p}} \frac{\partial C_{\mathrm{c}, \mathrm{p}}}{\partial y}+w_{\mathrm{p}} \frac{\partial C_{\mathrm{c}, \mathrm{p}}}{\partial z}\right) \\
& \left.\quad=D_{\mathrm{c}, \mathrm{p}} \frac{\partial^{2} C_{\mathrm{c}, \mathrm{p}}}{\partial x^{2}}+\frac{\partial^{2} C_{\mathrm{c}, \mathrm{p}}}{\partial y^{2}}+\frac{\partial^{2} C_{\mathrm{c}, \mathrm{p}}}{\partial z^{2}}\right)+G_{\mathrm{p}, \mathrm{c}}+\sum_{c}^{n} \dot{m}_{\mathrm{gp}, \mathrm{c}}+\sum_{c}^{n} \dot{m}_{\mathrm{gl}, \mathrm{c}}
\end{aligned}
$$

The general formulation (Equations (1)-(5)) can be simplified (Table 2) for most of the cases with the following assumptions (points $\mathrm{i}-\mathrm{x}$ based on the work of Soria-Verdugo et al. [15] and Almendros-Ibáñez et al. [36]):

i. Steady state.

ii. Two-dimensional mass and energy evolution: 2D symmetry along $z$ axis considered.

iii. Adiabatic operation: energy loss to the surroundings term is neglected.

iv. Heat transfer by radiation is negligible compared to convection heat transfer since it can be up to 20-40 times lower than the convection term for the operating conditions analysed.

v. Heat transfer by conduction in both phases is negligible according to Ref. [36].

vi. Solid phase is composed of inert, non-porous material particles. Thus, there is no pore-diffusion of heat and mass.

vii. No radial temperature distribution: Uniform temperature in the whole particle.

viii. One-dimensional gas and solid mass flow: $u_{\mathrm{g}}>>v_{\mathrm{g}}, w_{\mathrm{g}}$ and $v_{\mathrm{p}}>>u_{\mathrm{p}}, w_{\mathrm{p}}$ can be assumed.

ix. Mass diffusion is much lower than mass convection (represented by $u_{\mathrm{g}}$ ). In this way, second mass derivatives in Equations (4.4) and (4.5) are not accounted for.

$\mathrm{x}$. No reaction between species. Mass variation is only due to condensation.

xi. Gas and solid phase fractions are assumed to be constant during operation.

xii. Liquid phase fraction $\left(\varepsilon_{1}\right)$ is assumed to be included in the solid phase since the forming liquid film along the MBHEF dimensions is much less than the particle surface: it can represent around $1 \mathrm{E}-4$ or $1 \mathrm{E}-3 \%$ of the bed, which means a liquid film width from $1 \mathrm{E}-11$ to $1 \mathrm{E}-9 \mathrm{~m}$ according to the study conducted in this paper. Then, the liquid phase properties are assumed to be identical to that of the solid phase $\left(T_{1}=\theta\right.$, $\left.u_{\mathrm{l}}=u_{\mathrm{p}}, u_{\mathrm{l}}=v_{\mathrm{p}}, w_{\mathrm{l}}=w_{\mathrm{p}}\right)$. Hence, the heat diffusion terms related to $\varepsilon_{1}$ (left side) and second derivatives liquid phase (right side) in Equation (3) can be neglected.

xiii. Ideal gas behaviour is stated.

xiv. Tar condensation takes place when gas temperature equals or is less than the tar dew point for the corresponding tar concentration [10].

xv. Physical and transport properties for gas species and gassolid heat and mass transfer coefficients are evaluated with temperature at each point in the MBHEF (Table 3).

Finally, it has to be considered that the tar dew point is influenced by tar concentration so that in each mesh node a calculation strategy for solving conservation equations is required. The dependence of tar dew point with its concentration and tar class was investigated by Kiel et al. [21].

\subsection{Tars species}

As explained previously, tar fraction in biomass comprises a wide variety of compounds with different properties affecting to 
Table 2

Energy and mass conservation equations.

\begin{tabular}{|c|c|c|c|}
\hline Gas phase & & Solid phase & \\
\hline \multicolumn{4}{|l|}{ Energy balance } \\
\hline$\varepsilon \rho_{\mathrm{g}} c_{\mathrm{pg}}\left(u_{\mathrm{g}} \frac{\partial T}{\partial x}\right)=h_{\mathrm{p}} a_{\mathrm{e}}(\theta-T)-\sum_{c}^{n} \dot{m}_{c} h_{\mathrm{fg}, c}$ & (6) & $(1-\varepsilon) \rho_{\mathrm{p}} c_{\mathrm{pp}}\left(v_{\mathrm{p}} \frac{\partial \theta}{\partial y}\right)=h_{\mathrm{p}} a_{\mathrm{e}}(T-\theta)+\sum_{c}^{n} \dot{m}_{c} h_{\mathrm{fg}, c}$ & (7) \\
\hline \multicolumn{4}{|l|}{ Mass balance (for tar compound) } \\
\hline$u_{\mathrm{g}} \frac{\partial C_{\mathrm{c}}}{\partial x}=-\dot{m}_{\mathrm{c}}=a_{\mathrm{e}} k_{\mathrm{m}}\left(C_{\mathrm{c}}^{*}-C_{\mathrm{c}}\right)$ & $(8)$ & $v_{\mathrm{p}} \frac{\partial C_{\mathrm{c}, \mathrm{p}}}{\partial y}=\dot{m}_{\mathrm{c}}=-u_{\mathrm{g}} \frac{\partial C_{\mathrm{c}}}{\partial x}$ & (9) \\
\hline
\end{tabular}

devices. Hence, the choice of representative tars is critical for designing such equipment. Here, not all tar classes are considered since the work is focused in characterizing the performance of a MBHEF as a tar removal method. Only tar classes with a tar dew point over $0{ }^{\circ} \mathrm{C}$ are taken into account: tar classes 2, 4 and 5 are lumps of interest. One specie is chosen as representative of each tar class: phenol, naphthalene and pyrene for tar class 2, 4 and 5, respectively, since they are usually predominant in concentration in BFBG processes [21,45].

The prediction of tar dew point variations due to tar concentration change because of condensation is made by a 4-order polynomial fitting of data based on the simple model developed by the ECN research institution (www.thersites.nl). The polynomic fitting coefficients for each tar class are indicated in Table 4, and the equation is:

$$
\begin{aligned}
T_{\mathrm{dp}, \mathrm{tar}}= & P(1)\left(\log _{10} C_{\mathrm{tar}}\right)^{4}+P(2)\left(\log _{10} C_{\mathrm{tar}}\right)^{3} \\
& +P(3)\left(\log _{10} C_{\mathrm{tar}}\right)^{2} P(4)\left(\log _{10} C_{\mathrm{tar}}\right)+P(5)
\end{aligned}
$$

\subsection{Filtration model}

Dusty gas flows through the filter, the particles are collected on the granular medium, where it has interstitial voids with several dynamic shapes. A perfect modelling of solid-gas contacting is complicated because of the accumulation of deposited particles during the filtration process causes a continuing change in the structure of the medium. This situation is more complicated in the case of polydispersed aerosol since the effect of deposition is dependent not only on the total amount of deposition but on the size distribution of the deposited particle size distribution.

Table 3

Correlations for estimating viscosity, thermal conductivity, diffusivity, heat capacity of gas species, latent heat and heat and mass transfer coefficients for packed beds.

\begin{tabular}{llll}
\hline Property & Pure components & Mixtures & Reference \\
\hline Viscosity & $\mu_{\mathrm{c}}$ & $\mu_{\mathrm{g}}$ & {$[37]$} \\
Thermal conductivity & $k_{\mathrm{c}}$ & $k_{\mathrm{g}}$ & {$[37]$} \\
Diffusivity & $D_{\mathrm{ab}}{ }^{* 1}$ & $D_{\mathrm{g}}{ }^{* 2}$ & ${ }^{* 1}[38]$ \\
& & & ${ }^{2}[39]$ \\
Heat capacity & $C_{\mathrm{p}}$ & & {$[40]$} \\
Latent heat & $h_{\mathrm{fg}}$ & & {$[41]$} \\
Heat transfer coefficient & $h_{\mathrm{p}}$ & {$[42]$} \\
Mass transfer coefficient & $k_{\mathrm{m}}$ & & {$[43]$} \\
Effective interfacial area & $a_{\mathrm{e}}$ & & \\
\hline
\end{tabular}

Besides, the dynamic evolution of voids in the filter is further complicated by the tar condensation. If the concentration of tar condensed and particles filtrated are too high the flow dy-namics, the local filtration efficiency and the heat transfer, could be drastically affected. For the dust and tar concentrations considered the gas velocity can be taken uniform in the moving bed.

Then, this difficulty in predicting these parameters and in measuring the local void fraction leads to adopt a formulation of the macroscopic equations for modelling particle collection in the moving bed. An approach involving the macroscopic conservation and rate equations that describe the dynamic behaviour of granular filtration [46] can be depicted in Table 5. The rate at which the particle concentration in the gas decreases is given by the filter coefficient, $\lambda$, Lozano et al. [31].

These equations relate the dust mass balances in both phases: the amount of dust deposited within a given bed volume, $C_{\mathrm{p}, \mathrm{p}}$, and the dust concentration remaining in the gas, $C_{\mathrm{p}, \mathrm{g}}$ while the particle concentration profile in the gas follows an exponential law.

Dirty bed particles can be cleaned by vibration [32], recirculated to the moving bed filter if the dust and tar concentration are not too high or used as inert material in a fluidized bed if the gasification is carried out in such equipment.

\subsection{Calculation strategy}

The conservation Equations (6)-(9), (11)-(12), listed above, are expressed in terms of volumetric flow and they are used to derive the conservation Equations (13)-(19) of the model approach presented here. For convenience, the conservation Equations (6)-(9), (11)-(12) are redefined in terms of mass flow multiplying by the control volume. These equations are approximated by first-order forward finite-difference expressions since they are first-order equations. Finally, the conservation equations are solved as nondimensional Equations (13)-(19), solving the energy balances by means of inverse matrix method. The definition of the dimensionless variables and coefficients (NTU, CNTU, STe and CPS) is indicated in the Appendix.

Table 4

Polynomic fitting coefficients for 4-grade polynomial for each tar class.

\begin{tabular}{lllllll}
\hline Tar class & $P(1)$ & $P(2)$ & $P(3)$ & $P(4)$ & $P(5)$ & $R^{2}$ \\
\hline 2 & 0.0317 & 0.0862 & 1.1361 & 13.3110 & 236.4992 & 0.9999 \\
4 & 0.0392 & 0.0744 & 1.1563 & 13.2505 & 247.5884 & 1.0000 \\
5 & 0.0452 & 0.1090 & 1.6976 & 19.7733 & 324.2779 & 1.0000 \\
\hline
\end{tabular}


Table 5

Mass balance of dust in the gas and solid phases.

\begin{tabular}{|c|c|c|c|}
\hline \multicolumn{2}{|c|}{ Dust mass balance in gas phase } & \multicolumn{2}{|c|}{ Dust mass balance in solid phase } \\
\hline$\frac{\partial C_{\mathrm{p}, \mathrm{g}}}{\partial x}=-\lambda C_{\mathrm{p}, \mathrm{g}}$ & (11) & $v_{\mathrm{p}} \frac{\partial C_{\mathrm{p}, \mathrm{p}}}{\partial y}=-u_{\mathrm{g}} \frac{\partial C_{\mathrm{p}, \mathrm{g}}}{\partial x}$ & (12) \\
\hline
\end{tabular}

Energy balance for gas and solid phases

$$
\begin{aligned}
& \left.\left(\begin{array}{cc}
1+\frac{\mathrm{CNTU}_{x+\Delta x}^{*}}{2} & -\frac{\mathrm{CNTU}_{x+\Delta x}^{*}}{2} \\
-\frac{\mathrm{CNTU}_{x+\Delta x}^{*} \mathrm{NTU}_{x+\Delta x}^{*}}{2} & 1+\frac{\mathrm{CNTU}_{x+\Delta x}^{*} \mathrm{NTU}_{x+\Delta x}^{*}}{2}
\end{array}\right) \begin{array}{c}
T_{x+\Delta x}^{*} \\
\theta_{x+\Delta x}^{*}
\end{array}\right) \\
& =\left(\begin{array}{c}
\frac{\mathrm{CPG}_{x}^{*}}{\mathrm{CPG}_{x+\Delta x}^{*}}\left(T_{x}^{*}-T_{\mathrm{ref}}^{*}\right)-\frac{\mathrm{CNTU}_{x+\Delta x}^{*}}{2}\left(T_{x}^{*}-\theta_{y}^{*}\right)+\frac{\left(T_{0}^{*}-\theta_{0}^{*}\right)}{S T e_{x+\Delta x}^{*}}+T_{\mathrm{ref}}^{*} \\
\frac{\mathrm{CPS}_{y}^{*}}{\mathrm{CPS}_{y+\Delta y}^{*}}\left(\theta_{y}^{*}-\theta_{\mathrm{ref}}^{*}\right)+\frac{\mathrm{CNTU}_{x+\Delta x}^{*}}{2}\left(T_{x}^{*}-\theta_{y}^{*}\right)+\frac{\left(T_{0}^{*}-\theta_{0}^{*}\right)}{S T e_{x+\Delta x}^{*}}+\theta_{\mathrm{ref}}^{*}
\end{array}\right)
\end{aligned}
$$

Mass balance for tar species in gas and solid

$$
\begin{aligned}
C_{\mathrm{g}, x+\Delta x}^{*}= & \frac{u_{\mathrm{g}, x}}{u_{\mathrm{g}, x+\Delta x}} C_{\mathrm{g}, x}^{*}+\frac{\Delta x^{*} k_{\mathrm{m}} a_{\mathrm{e}} L}{u_{\mathrm{g}, x+\Delta x}}\left(C_{\mathrm{s}, y}^{*}-C_{\mathrm{g}, x}^{*}\right) \\
& \left.-1-\frac{u_{\mathrm{g}, x}}{u_{\mathrm{g}, x+\Delta x}}\right) \frac{C_{\mathrm{s}, 0}}{\left(C_{\mathrm{g}, 0}-C_{\mathrm{s}, 0}\right)} \\
C_{\mathrm{s}, y+\Delta y}^{*}= & C_{\mathrm{s}, y}^{*}+\frac{\Delta y^{*} k_{\mathrm{m}} a_{\mathrm{e}} H}{u_{\mathrm{p}}}\left(C_{\mathrm{g}, x}^{*}-C_{\mathrm{s}, y}^{*}\right)
\end{aligned}
$$

Mass balance for water in gas and solid phases

$$
\begin{aligned}
C_{\mathrm{g}, x+\Delta x}^{*}= & \left.\frac{u_{\mathrm{g}, x}}{u_{\mathrm{g}, x+\Delta x}} C_{\mathrm{g}, x}^{*}+\frac{\Delta x^{*} L}{u_{\mathrm{g}, x+\Delta x}} k_{\mathrm{m}} a_{\mathrm{e}}\left(C_{\mathrm{s}, y}^{*}-C_{\mathrm{g}, x}^{*}\right)+\frac{\dot{m}_{\mathrm{evap}}}{C_{\mathrm{g}, 0}-C_{\mathrm{s}, 0}}\right) \\
& \left.-1-\frac{u_{\mathrm{g}, x}}{u_{\mathrm{g}, x+\Delta x}}\right) \frac{C_{\mathrm{s}, 0}}{\left(C_{\mathrm{g}, 0}-C_{\mathrm{s}, 0}\right)}
\end{aligned}
$$

$\left.C_{\mathrm{s}, y+\Delta y}^{*}=C_{\mathrm{s}, y}^{*}+\frac{\Delta y^{*} H}{u_{\mathrm{p}}} \quad k_{\mathrm{m}} a_{\mathrm{e}}\left(C_{\mathrm{g}, x}^{*}-C_{\mathrm{s}, y}^{*}\right)+\frac{\dot{m}_{\mathrm{cond}}}{\left(C_{\mathrm{g}, 0}-C_{\mathrm{s}, 0}\right)}\right)$

Mass balance for particulate material in gas and solid phases

$$
\begin{aligned}
C_{\mathrm{pg}, x+\Delta x}^{*}= & \left.C_{\mathrm{pg}, x}^{*}+-\lambda \Delta x^{*} L \quad C_{\mathrm{pg}, x}^{*}+\frac{C_{\mathrm{pp}, 0}}{\left(C_{\mathrm{pg}, 0}-C_{\mathrm{pp}, 0}\right)}\right) \\
& -\frac{C_{\mathrm{pp}, 0}}{\left(C_{\mathrm{pg}, 0}-C_{\mathrm{pp}, 0}\right)} \\
C_{\mathrm{pp}, y+\Delta y}^{*}= & \left.C_{\mathrm{pp}, y}^{*}+\frac{\lambda \Delta y^{*} H}{u_{\mathrm{p}}} C_{\mathrm{pg}, x}^{*}-\frac{C_{\mathrm{pp}, 0}}{\left(C_{\mathrm{pg}, 0}-C_{\mathrm{pp}, 0}\right)}\right)
\end{aligned}
$$

The energy and mass balances in each node are solved according to the calculation method explained in Fig. 4. The heat transfer and tars condensation are simulated with the characteristic node temperature for both phases, that is, the node " $(x+x+\Delta x) / 2$, $(y+y+\Delta y) / 2$ ". As the gas properties in the node " $x+\Delta x, y$ " depend on the temperature in that node and the gas and solid temperatures are unknown, for the first calculation the characteristic node temperatures for both phases are assumed to be the ones in the node " $x, y$ " in order to calculate the gas and solid temperatures for the nodes " $x+\Delta x, y$ " and " $x, y+\Delta y$ ". In this way, there is a calculation error which is minimized by means of an iteration method to satisfy the energy balance for both phases. Therefore, this calculation sequence is repeated while the error in the outlet temperature of gas and solid phases does not satisfy the tolerance adopted (1E-3 here). Thus, the simulation of the performance of the MBHEF system is carried out along the $y$ and $x$ directions until the value of a variable $X$ is less than the value stated as goal. This variable, called $X_{\text {goal }}$, can be either the gas temperature exhaust $\left(60^{\circ} \mathrm{C}\right.$ as the inlet gas temperature in engine applications) or the tar reduction efficiency in accordance to the two possible cases of interest: case 1 and 2 .

\section{Results and discussion}

The performance of a MBHEF is studied using the composition $\left(\mathrm{CO}, \mathrm{CO}_{2}, \mathrm{H}_{2}, \mathrm{CH}_{4}\right)$ from test 1 of experiments conducted by Campoy et al. [47]. The gas temperature and the water content are set as $700{ }^{\circ} \mathrm{C}$ and $10 \%$ of gas volume respectively, since they are typical results in gasification. Concerning the pollutant species, the typical tar content in syngas is around $20-50 \mathrm{~g} / \mathrm{Nm}^{3}$ according to GómezBarea and Leckner [48]. Thus, we set the inlet tar concentration as $10 \mathrm{~g} / \mathrm{Nm}^{3}$ for each representative species of condensable tar class so that all tars species account for $30 \mathrm{~g} / \mathrm{Nm}^{3}$. Finally, inlet fines or dust particles content and others dust properties such as particle size and density are set from the work of Lozano et al. [31]. The gas velocities employed, $0.5-3 \mathrm{~m} / \mathrm{s}$, assure proper MBHEF operation with no ceasing of solid flow [49] and the range $100 \mu \mathrm{m}-1 \mathrm{~mm}$ of particle bed size is of interest. Table 6 shows the data of gas and solid properties used for simulations.

The MBHEF can be analysed from two different points of view. Firstly, the MBHEF can be built in order to get a proper temperature of the syngas to be fed to ICE or GT, normally, around $60^{\circ} \mathrm{C}$ (we call this situation case 1). In this case, the removal efficiency of tars and fines particle is not of interest. Consequently, depending on the inlet tars and particle content, the MBHEF design could be enough or not to depurate the syngas flow. The equipment would act as a first cleaning measure and a second measure should be taken to adequate quality syngas for its power production use in mechanical engines. Secondly, the MBHEF can be designed to satisfy tars and particle levels (case 2). Thus, the gas temperature exhaust can be different (lower) from $60^{\circ} \mathrm{C}$, the value set as inlet gas temperature in ICE's and GT's. Then, the performance of the MBHEF should be analysed regarding two variables: the inlet gas temperature to ICE's and GT's and the tars and particle removal efficiency, which are calculated by comparison with the corresponding inlet content values for both streams.

\subsection{Syngas conditioning for engine applications requirements}

Fig. 5 shows the thermal performance of the MBHEF device: the temperature maps of gas (A) and solid phase (B) for the case of $700 \mu \mathrm{m}$ and $1.5 \mathrm{~m} / \mathrm{s}$ of gas velocity as for example. The gas stream entering the MBHEF lowers its temperature while the downward moving bed increases its temperature until there is not temperature difference between both phases, what depends on the device dimensions. Consequently, it can be seen that gas and solid streams leave the device with a different bulk temperature from the corresponding inlet values. Note that these equipment sizes may not mean energy and exergy optimised dimensions of MBHEF. 


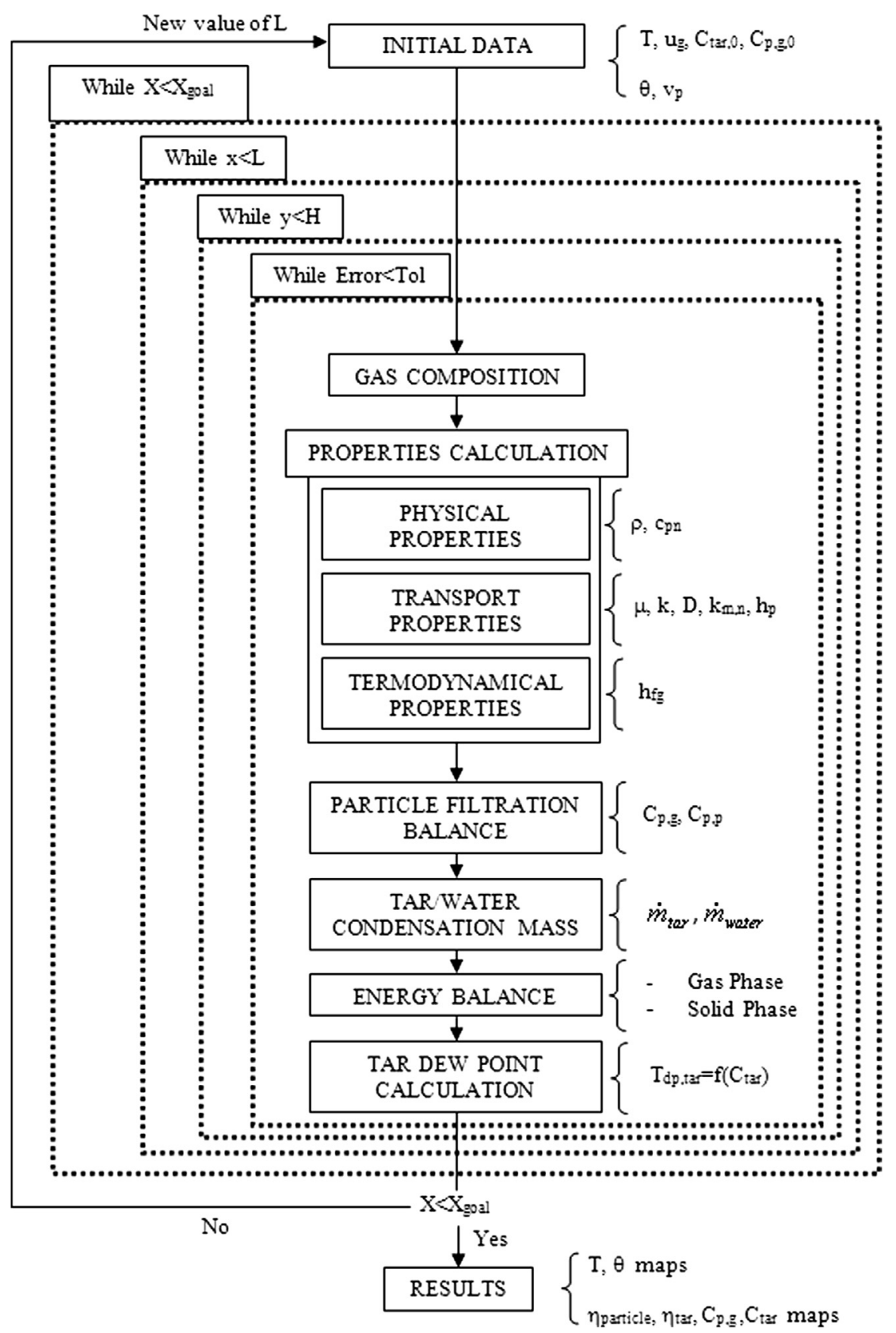

Fig. 4. Scheme of the calculation strategy for simulating the tar removal in a MBHEF system.

Table 6

Data of gas and solid properties.

\begin{tabular}{|c|c|c|c|c|c|}
\hline \multicolumn{2}{|c|}{$\begin{array}{l}\text { Gas composition } \\
\text { (\%, d.b.) }\end{array}$} & \multicolumn{2}{|c|}{$\begin{array}{l}\text { Contaminant } \\
\text { concentration }\left(\mathrm{g} / \mathrm{Nm}^{3}\right)\end{array}$} & \multicolumn{2}{|l|}{ Solid properties } \\
\hline $\mathrm{O}_{2}$ & 0.0 & Tars class 2 & 10 & Bed porosity, $\varepsilon$ & 0.4 \\
\hline $\mathrm{CO}$ & 15.8 & Tars class 4 & 10 & $\begin{array}{l}\text { Bed particle } \\
\text { size }\end{array}$ & $100 \mu \mathrm{m}-1 \mathrm{~mm}$ \\
\hline $\mathrm{CO}_{2}$ & 15.1 & Tars class 5 & 10 & $\rho_{\mathrm{p}}\left(\mathrm{kg} / \mathrm{m}^{3}\right)$ & 2150 \\
\hline $\mathrm{H}_{2}$ & 8.7 & $\begin{array}{l}\text { Particle } \\
\text { (fines or “dust”) }\end{array}$ & 8 & $c_{\mathrm{p}}(\mathrm{J} / \mathrm{kg} \mathrm{K})$ & 745 \\
\hline $\mathrm{CH}_{4}$ & 5.1 & Particle size $(\mu \mathrm{m})$ & 5 & $k_{\mathrm{p}}(\mathrm{W} / \mathrm{m} \mathrm{K})$ & 2.9 \\
\hline$Q_{\text {gas }}\left(\mathrm{Nm}^{3} / \mathrm{h}\right)$ & 4.6 & $\begin{array}{l}\text { Particle density } \\
\left(\mathrm{kg} / \mathrm{m}^{3}\right)\end{array}$ & 2100 & $v_{\mathrm{p}}(\mathrm{cm} / \mathrm{min})$ & 5 \\
\hline
\end{tabular}

As expected, tar condensation is linked to heat transfer between phases since it depends on the tar dew point and the tar concentration in the gas bulk according to Kiel et al. [21]. This will be explained as follows.

Fig. $6 \mathrm{~A}$ indicates the tar removal efficiency in the cross-sectional area along the $x$ coordinate, that is, the gas flow direction. This map denotes the areas inside the device where tars condensation would take place. These condensation areas correspond to gas temperatures below the respective tar dew point of each tar class. The colour indicates the order of magnitude of condensation. Instead of having a gradual condensation of tars, the condensation phenomenon takes places in a very narrow strip, where there is a high variation in temperature (see Fig. 5). The use of small particle sizes promotes this condensation behaviour. For example, the blue-coloured region corresponds to a hot gas with a temperature higher than the tar dew point for each tar species while the red-coloured 

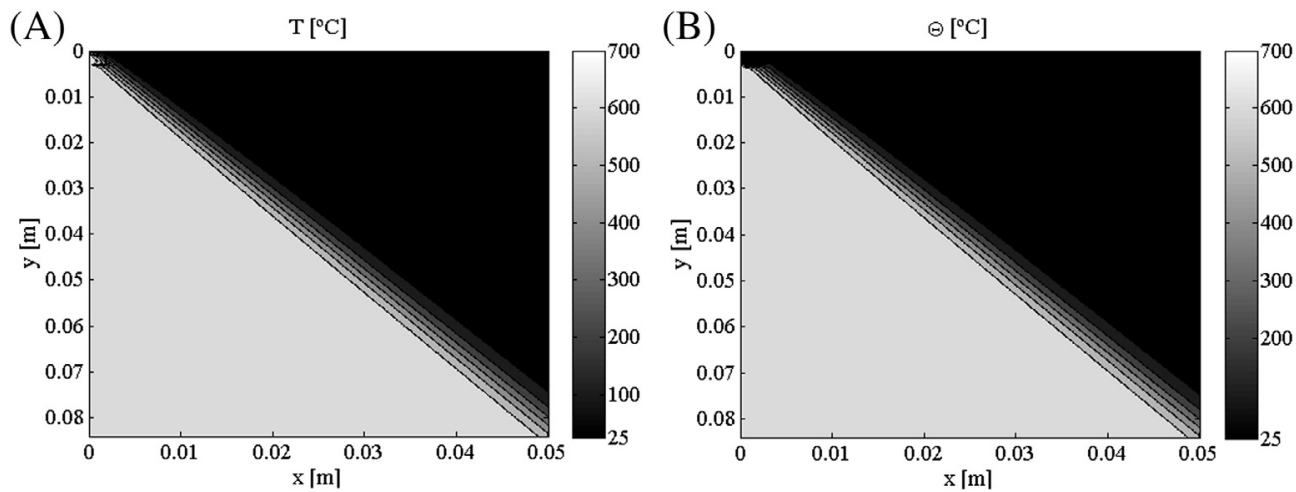

Fig. 5. Contour maps of gas temperature (A) and solid temperature (B) for $d_{\mathrm{p}}=700 \mu \mathrm{m}$ and $u_{\mathrm{g}}=1.5 \mathrm{~m} / \mathrm{s}$.

area, above the hot gas flow, would mean a colder syngas with lower tar content. Because of the small particle bed diameter, below $1 \mathrm{~mm}$, the specific area yields a narrow border between the coldest part of gas flow and the hottest region of gas flow as seen previ-ously. This fact is the consequence of the nature of particle beds which allows achieving huge specific areas enhancing heat and mass transfer. Therefore, the rapid heat transfer is accompanied by a fast tars condensation wherever the respective tar dew points are greater than local gas temperature.

The particulate matter reduction also takes place simultaneously with the heat and mass transfer involving tars condensation. According to the filtration model adopted for granular material, the dust collection efficiency follows the pattern shown in the map stated above, Fig. 6B. Due to the use of so small particle bed material, the collection of fine dust occurs gradually along the de-vice length.

Fig. 7 shows the tar reduction efficiency profile along the equipment length, that is, the gas flow direction. The tar content in the gas bulk rapidly decreases because of the mentioned high specific area of the moving bed: for a gas flow of $4.6 \mathrm{Nm}^{3} / \mathrm{h}$ and a 5 $\mathrm{cm}$ length device, tar reduction efficiencies up to $90 \%$ or even more can be attained. In addition to this, Fig. 7B depicts the increasing dust collection efficiency along the device length: initially linear and then, a softer growing rate. Thus, the compact MBHEF could be employed as a first tar abatement measure fol-lowed by a second exhaustive method, for instance, a tar cracker.

These trends in thermal and tar removal performance happen for the operating conditions range studied since the specific a r e a is so high that promotes the heat exchange in much reduced di-mensions of equipment.
As follows, dimensionless gas temperature and tar abatement efficiencies maps are presented in Figs. 8(A-D) and 9(A-D). A s i t can be seen, the patterns are opposed: the lower the gas temperature, the higher the tar removal efficiency with the position. These maps show: firstly, the influence of the particle bed size and the superficial gas velocity, and secondly, the choice of operating conditions and equipment size for achieving the tar removal efficiency desired which would accomplish quality syngas requirements in ICE's and GT's.

In both Figs. 8(A-D) and 9(A-D), it can be understood that the superficial gas velocity has a negative effect in the heat exchange and tar condensation. High gas velocities involve low residence times to reach the same gas outlet temperature and then, the same value of tar removal efficiency. This means that syngas with acceptable tar content levels for engine applications requires much compact devices with low gas velocities than with high values. The same is expected to occur with the particle bed size. Furthermore, the trends for gas temperature and tar content reduction are opposed since the tar abatement efficiency is linked to the tar dew point.

Fig. 8(A-D) depicts the heat transfer process to cool down completely the syngas: from the inlet gas temperature to the inlet solid temperature. The maps presented in Fig. 8(A-D) shows the average gas temperature evolution with length as well as the influence of the superficial gas velocity. As it can be observed, the particle size of moving bed practically has the same influence on the gas temperature profile but the $1 \mathrm{~mm}$ of particle bed diameter. For this particle diameter, a curve-like evolution is noticeable when the gas temperature is close to the inlet solid temperature. For particle sizes of 400 and $700 \mu \mathrm{m}$ the curves endings look very
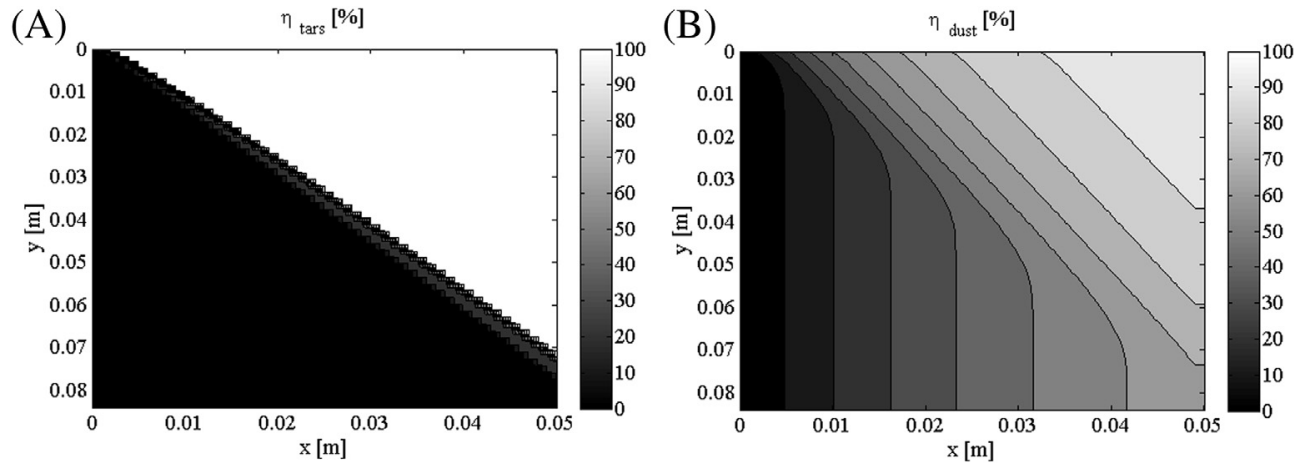

Fig. 6. Contour map of tar removal efficiency (A) and dust collection efficiency (B) for $d_{\mathrm{p}}=700 \mu \mathrm{m}$ and $u_{\mathrm{g}}=1.5 \mathrm{~m} / \mathrm{s}$. 
(A)

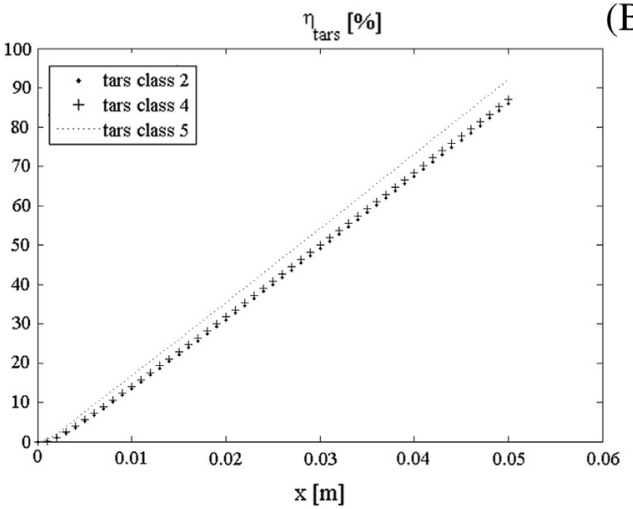

(B)

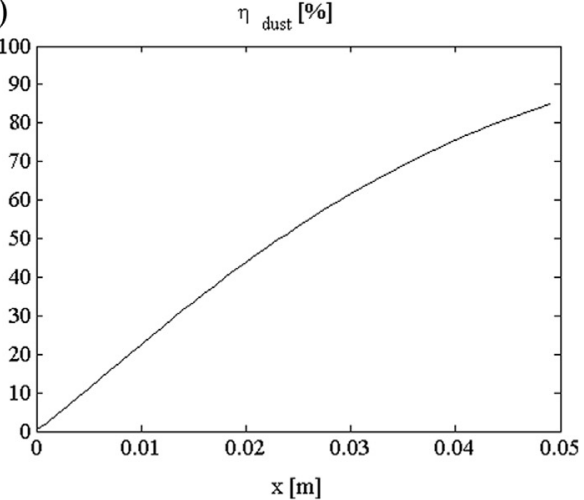

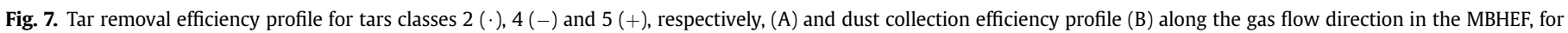
$d_{\mathrm{p}}=700 \mu \mathrm{m}$ and $u_{\mathrm{g}}=1.5 \mathrm{~m} / \mathrm{s}$.

similar while for $100 \mu \mathrm{m}$ is unnoticeable and for $1 \mathrm{~mm}$ the slope is a little more pronounced. Besides, the effect of the superficial gas velocity when reaching the inlet solid temperature is also observed in a lower slope of the gas temperature profile and a higher device length to reach the same outlet gas temperature. This is more noticeable for greater gas velocities (1-3 m/s). Finally, accordingly to the simulation results, it could be stated the existence of two linear profiles: a very long first one and a second one when the gas temperature is very close to the inlet solid temperature.

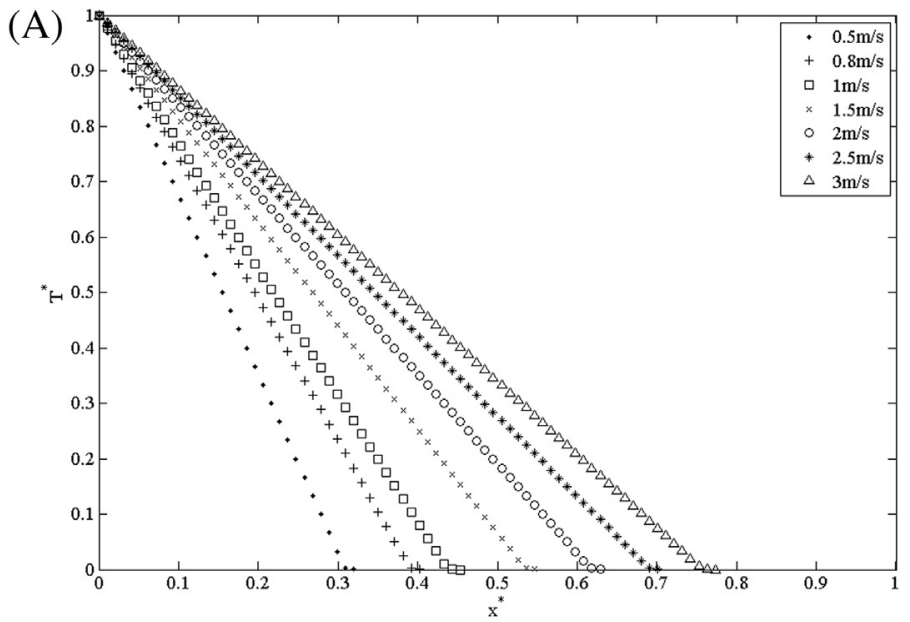

(C)

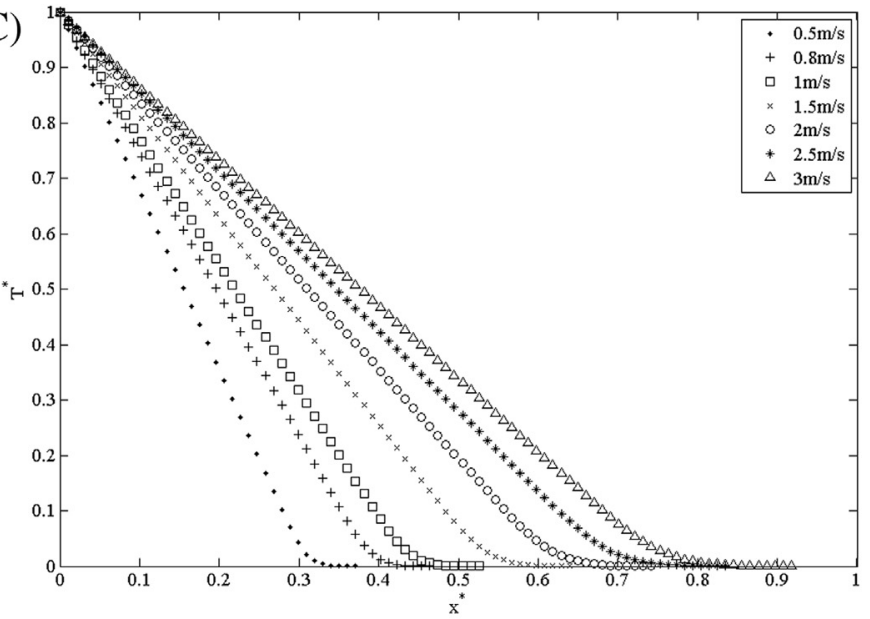

Concerning the tar removal efficiency maps, Fig. 9(A-D) shows the same trends described above, but now, the tar removal efficiency has the opposite evolution. The tar abatement efficiency, presented as the average tar removal efficiency of tar classes 2,4 and 5, rises with the decrease of the superficial gas velocity and the particle size. As explained previously, the increase of the gas superficial velocity yields a decrease of the residence time of the gas inside the device so that lower tar content is removed from the gas bulk. In addition to this, the removal of tars is enhanced by the use
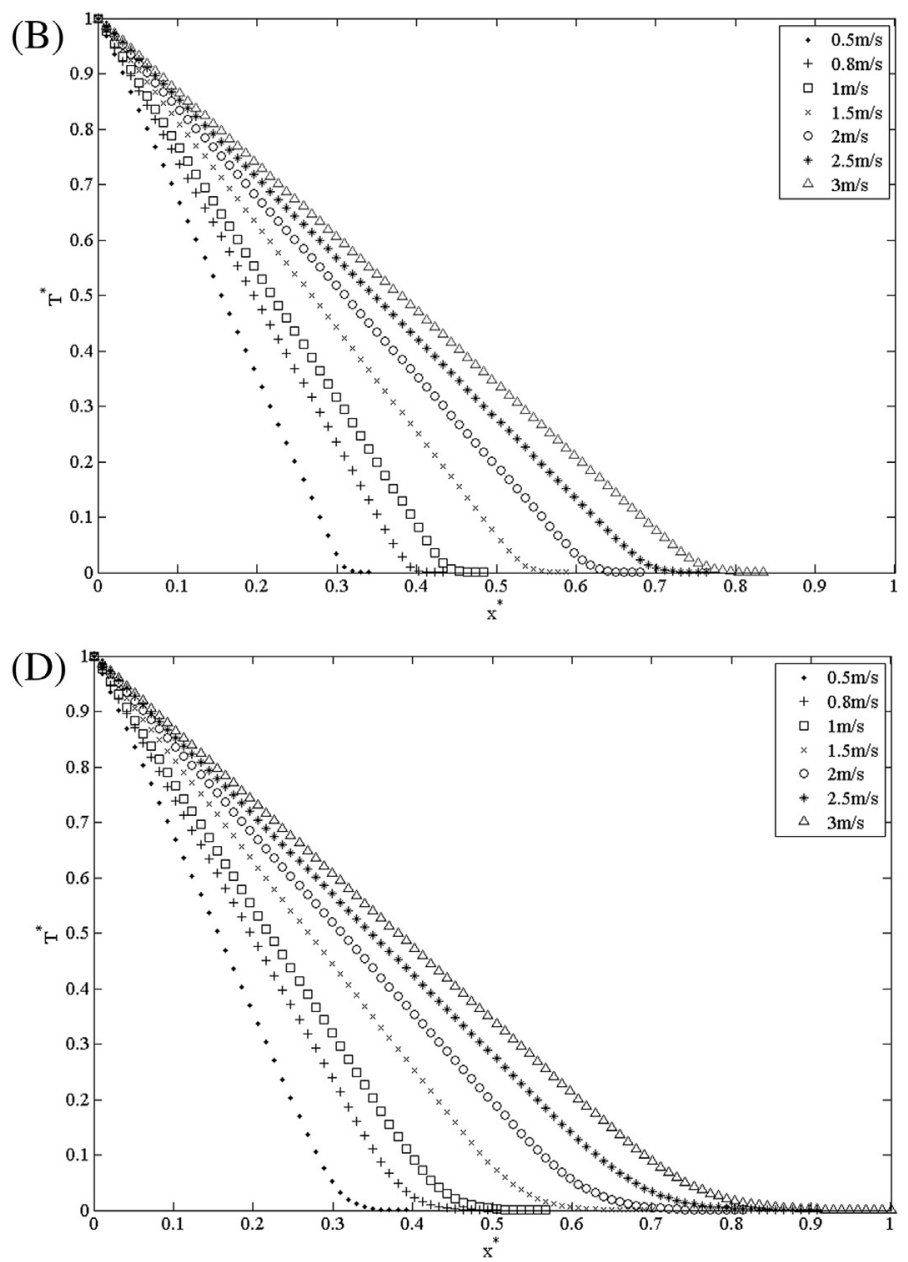

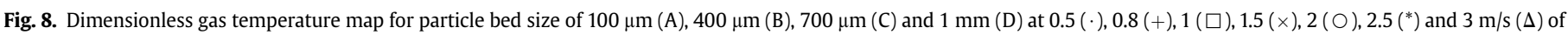
superficial gas velocity. 
(A)

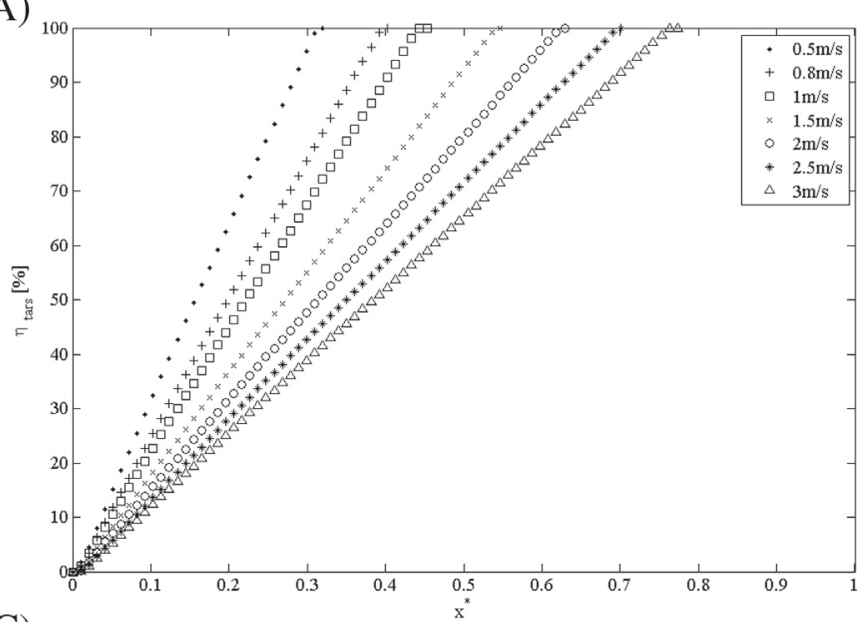

(C)

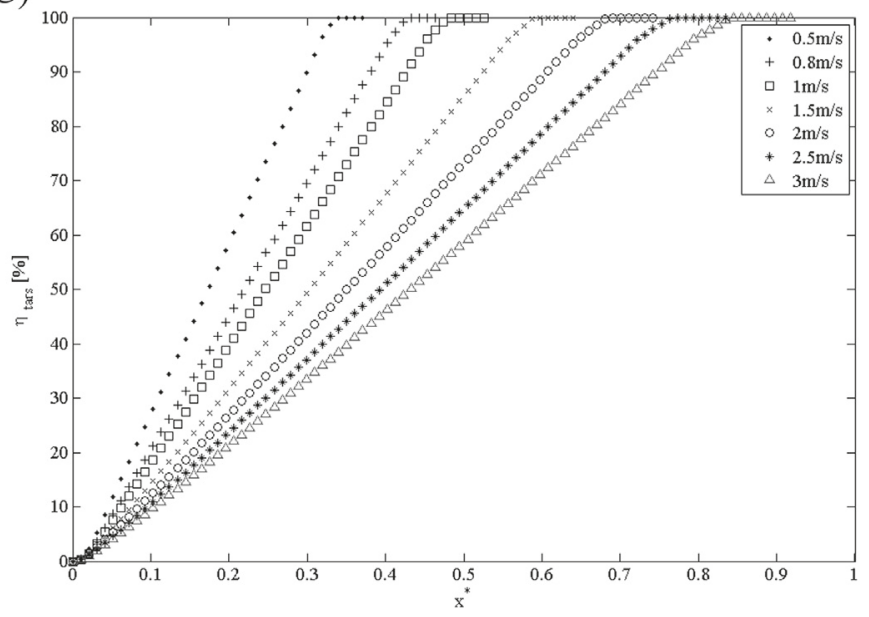

(B)

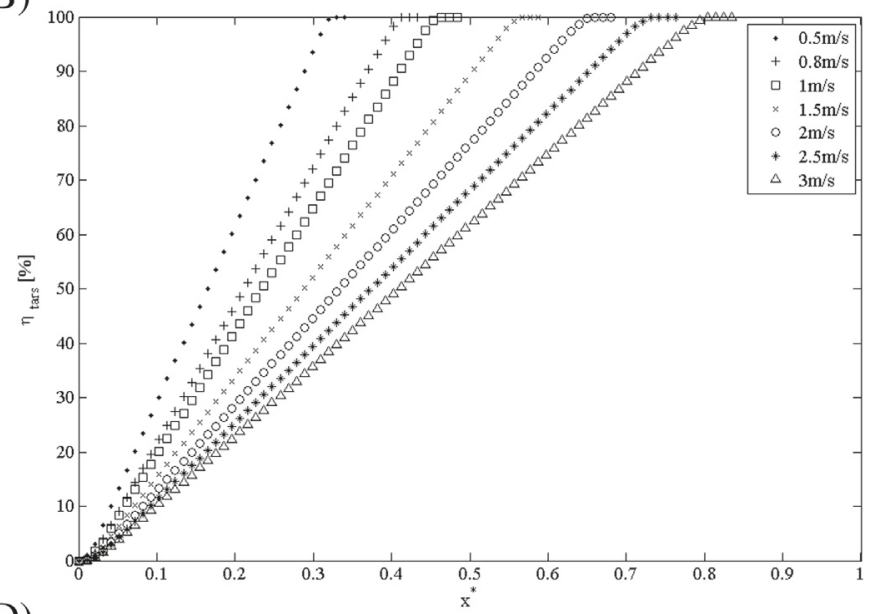

(D)

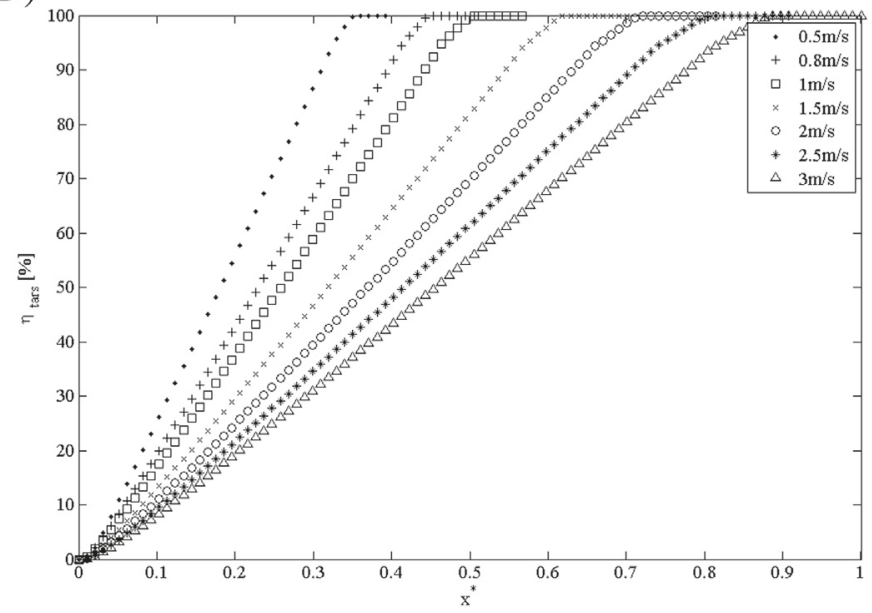

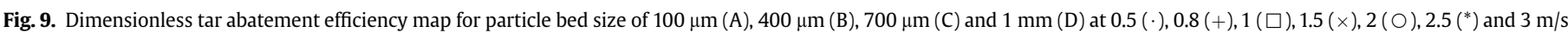
$(\Delta)$ of superficial gas velocity.

of small bed particle sizes promoting high heat and mass transfer coefficients. Thus, this leads to compact equipment sizes saving costs in materials, building and operation.

These maps compare the equipment size required for achieving the tar removal efficiency desired or specified by the engine application. Thereafter, the same level of tar reduction can be obtained at any gas velocity by making longer the MBHEF length. For example, for getting a tar removal efficiency of $50 \%$ for a gas flow at $0.5 \mathrm{~m} / \mathrm{s}$, a device twice times shorter than blowing gas at $3 \mathrm{~m} / \mathrm{s}$ would be needed. However, if a tar content reduction of at least $95 \%$ is desired, the increase of the superficial gas velocity from 0.5 to $3 \mathrm{~m} / \mathrm{s}$ would require a MBHEF three times longer instead of just doubling the size. This point is very important since the size of the equipment is related to the pressure drop and therefore the operational costs as it will be analysed later on.

Finally, note that the dimensionless map for each particle size is constructed using the maximum length obtained in all designs, that is, for the range of particle size studied, the cases with $1 \mathrm{~mm}$ of bed particle diameter (Fig. 9D). Furthermore, comparing the device performance for all particle bed diameters studied, the differences are slight at low gas velocities $(0-1.5 \mathrm{~m} / \mathrm{s})$ while at high gas velocities $(2-3 \mathrm{~m} / \mathrm{s})$ they are noticeable. In the current study, tars with tar dew point above ambient temperature, $25^{\circ} \mathrm{C}$, have been investigated. Then, tar species with a tar dew point below the inlet solid temperature (ambient temperature in this work) would not be removed. Therefore, the resulting maps would show tar removal efficiency profile below 100\% though the inlet solid temperature would be reached for the gas phase. As consequence, tar classes more refractory such as classes 1 and 3 would not be removed by the proposed method and further syngas conditioning aimed to eliminate tar classes 1 and 3 should be employed for satisfying tar content required in engines applications.

On the other hand, Fig. 10A shows the linear relationship of the length/width ratio with the gas velocity and the particle bed diameter to cool down the gas until the inlet temperature of solid flow. This figure stands out several important aspects in designing a MBHEF. Firstly, the higher the gas velocity the longer the aspect ratio, that is, the longer the length since the residence time is decreasing with the gas velocity of gas for each particle size. Secondly, the relative importance of gas velocity and particle size remains practically unchanged but at low gas velocities (below $1 \mathrm{~m} / \mathrm{s}$ ) the performance of MBHEF tends to be insensitive to the particle size. Thus, the gas velocity rules tars condensation. This will be relevant for choosing the map of operating conditions with saving operational costs. Thirdly, at high superficial gas velocities (1.5$3 \mathrm{~m} / \mathrm{s}$ ) the particle bed diameter of moving bed gains relevance in the MBHEF design since the gap between lines grows with the gas velocity as denoted by Fig. 10A. Although this figure allows checking the relative importance of the two key operating parameters for design purposes of a MBHEF, Fig. 10B is a useful help in the choice of proper operating conditions of a MBHEF in terms of pressure drop and energy consumption for blowing the syngas flow. 
(A)

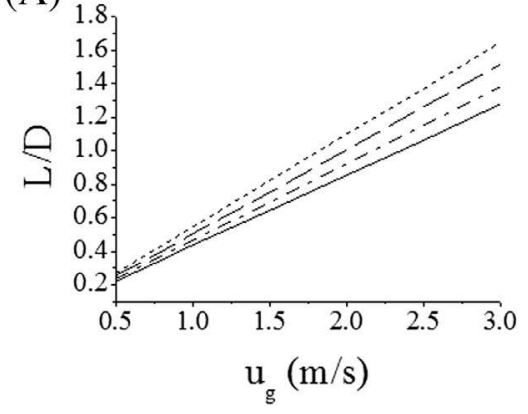

(B)

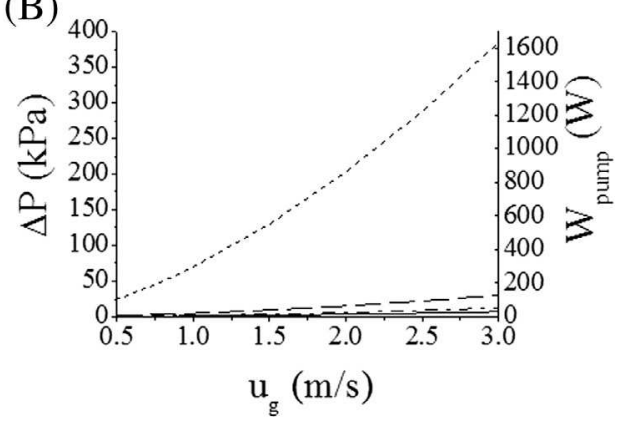

Fig. 10. Influence of superficial gas velocity and particle size $(100 \mu \mathrm{m}:-, 400 \mu \mathrm{m}:-, 700 \mu \mathrm{m}:--$, and $1 \mathrm{~mm}: \cdots)$ on the length-width ratio (A) and the pressure drop and power consumption (B).

The pressure drop [50] along the moving bed increases with the particle bed diameter and the gas velocity from 24 to $385 \mathrm{kPa}$ for $100 \mu \mathrm{m}$ of particle size, from 1.6 to $30.5 \mathrm{kPa}$ for $400 \mu \mathrm{m}$, from 0.5 to $12.2 \mathrm{kPa}$ for $700 \mu \mathrm{m}$ and from 0.3 to $7.2 \mathrm{kPa}$ for $1 \mathrm{~mm}$ (Fig. 10B). This means that the pressure drop can be a factor of 30 times greater at $3 \mathrm{~m} / \mathrm{s}$ than at $0.5 \mathrm{~m} / \mathrm{s}$. Furthermore, the range analysed yields a power consumption of 98-1621 W, 6.5-12.9 W, 2.3-51.6 W and $1.2-30.3 \mathrm{~W}$ for $100 \mu \mathrm{m}, 400 \mu \mathrm{m}, 700 \mu \mathrm{m}$ and $1 \mathrm{~mm}$ respectively for conditioning a gas flow of $4.6 \mathrm{Nm}^{3} / \mathrm{h}$. Therefore, particle sizes above $400 \mu \mathrm{m}$ would yield acceptable tar content reduction with a relatively low pressure drop compared to the performance of a MBHEF employing $100 \mu \mathrm{m}$ particle size. Additionally, above $700 \mu \mathrm{m}$, the pressure drop remains softly sensitive with the superficial velocity while below $400 \mu \mathrm{m}$ the pressure drop is more influenced.

To sum up, the analysis of the influence of the operating conditions in the pressure drop indicates that low values of superficial gas velocity $(0.5 \mathrm{~m} / \mathrm{s})$ and high particle size $(700 \mu \mathrm{m}-1 \mathrm{~mm})$ should be recommended in order to save operational costs.

Fig. $11 \mathrm{~A}$ shows the influence of the outlet gas temperature in the average tar removal efficiency of all tar classes at $3 \mathrm{~m} / \mathrm{s}$ what would correspond to the most unfavourable case. As expected, the tar abatement level follows a decreasing linear relationship with the outlet gas temperature. This is logical since its means that the length of the MBHEF is not enough to allow the heat exchange between both gas and solid phases completely. This has the same effect that increasing the gas velocity what would mean lower residence time. Then, there is less gas-solid contact yielding fewer tars condensation. In addition to this, all lines hardly change their slopes but the one corresponding to $1 \mathrm{~mm}$ of particle bed diameter. Furthermore, considering the case of $1 \mathrm{~mm}$ of particle bed diameter, it could be understood that this line would yield the minimum tar removal efficiency for tar classes 2,4 and 5 . As an example, at $80{ }^{\circ} \mathrm{C}, 60{ }^{\circ} \mathrm{C}$ and $40{ }^{\circ} \mathrm{C}$, above $80 \%, 85 \%$ and $91 \%$ of tar content reduction would be achieved respectively.

On the other hand, Fig. 11B depicts the dependence of dust collection efficiency for particulate matters of 5 and $10 \mu \mathrm{m}$ with the superficial gas velocity. These curves correspond to particle bed sizes of $400 \mu \mathrm{m}$ and $1 \mathrm{~mm}$. The two solid curves are related to filtration in a moving bed of $400 \mu \mathrm{m}$ which denote higher dust collection efficiencies than at $1 \mathrm{~mm}$ of particle bed size, dash curves. In fact, the difference can be up to two times at low gas velocities $(0.5-1.5 \mathrm{~m} / \mathrm{s})$. Furthermore, the dust collection efficiency for dust of $10 \mu \mathrm{m}$ is higher than for $5 \mu \mathrm{m}$ since the relative particle size is lower as well as this gap is lower for low particle size $(400 \mu \mathrm{m})$. Then, low gas velocities and low bed particle sizes are desirable for getting dust collection efficiencies of at least to $80 \%$. In order to get higher efficiencies in collecting dust material, a second gas flow treatment should be applied.

As previously stated, the MBHEF equipment would yield high tar removal efficiencies, at least of the same order of those attained with the use of catalytic tar cracker, venture scrubber or sand bed filter at much lower temperatures and higher efficiencies than the ones achieved by means of wash tower, wet electrostatic precipitator, fabric filter, rotational particle separator and fixed bed adsorber [51].
(A)

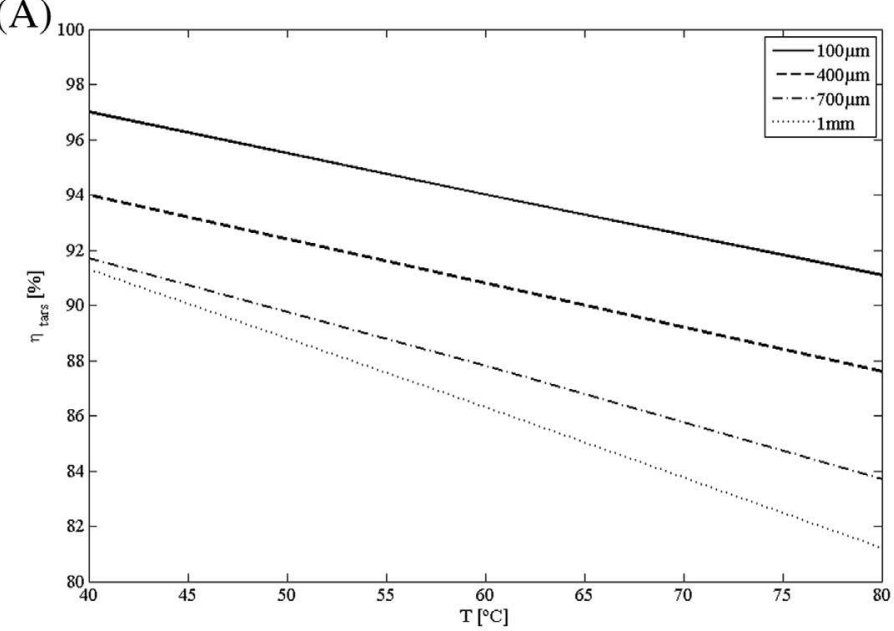

(B)

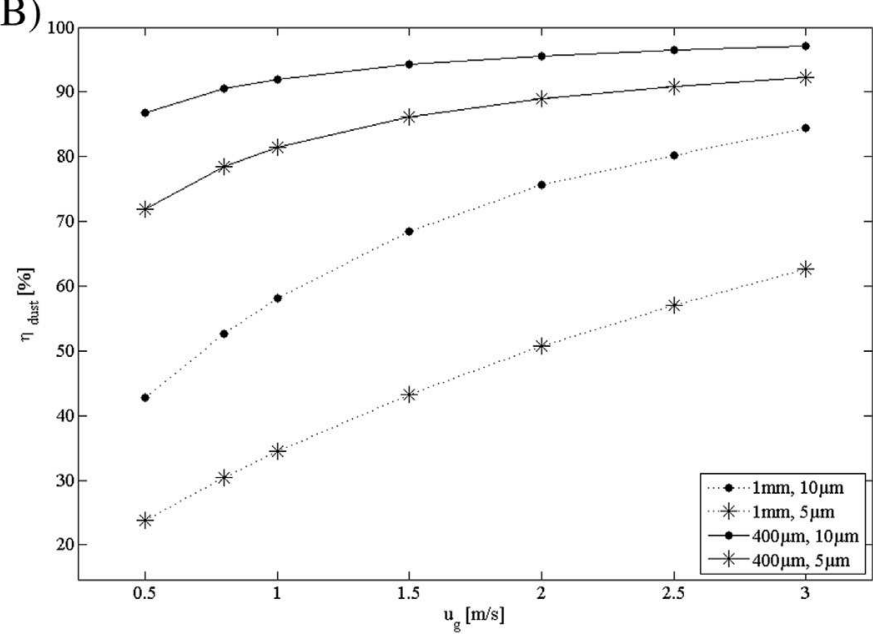

Fig. 11. Tar removal efficiency with outlet gas temperature at several particle sizes: $100 \mu \mathrm{m}(-), 400 \mu \mathrm{m}(--)$, $700 \mu \mathrm{m}(-\cdot)$ and $1 \mathrm{~mm}(--)$ at $3 \mathrm{~m} / \mathrm{s}$ superficial gas velocity (A) and dust collection efficiency with superficial gas velocity at $400 \mu \mathrm{m}(-)$ and $1 \mathrm{~mm}(--)$ for $5\left({ }^{*}\right)$ and $10 \mu \mathrm{m}(\cdot)$ of dust (B). 
Finally, one point has to be considered. Because of using a moving bed, an additional stream with tarry material condensed would be produced as waste. Then, it would require a recovery or cleaning treatment in order to clean the moving bed of tars. The current work proposes to recirculate the solid flow stream coming out from the moving bed to the BGFB reactor in order to clean it up and avoid extra waste disposal problems: cleaning equipment and costs. Therefore, the moving bed should employ the same particle size than the one used in the bed of the BGFB reactor.

\section{Conclusions}

A tar and particle removal analysis of a MBHEF system has been performed varying the particle size of the bed material and the superficial gas velocity. Tar specie representatives of classes 2, 4 and 5 have been chosen. The general problem is addressed and simplified for a gas-solid cross-flow, neglecting conduction and energy losses terms.

According to the sensitivity analysis carried out, compact equipment yielding tar removal efficiencies up to $94 \%$ are attainable with the proper choice of operating conditions, superficial gas velocities of $0.5-3 \mathrm{~m} / \mathrm{s}$ and particle bed sizes of $100 \mu \mathrm{m}-1 \mathrm{~mm}$ for example, for an outlet gas temperature of $60^{\circ} \mathrm{C}$. The superficial gas velocity and the particle size have been demonstrated as key parameters in designing compact equipment. Low superficial velocities promote high residence time and low pressure drop and then, slighter power consumption in contrast to higher gas velocities (above $1.5 \mathrm{~m} / \mathrm{s}$ ). The opposed effect is found with the particle size of the bed. The smaller the particle size the higher gas-solid contact and therefore the higher the tar condensation rates and the tar removal efficiencies. However, small particle bed sizes would involve higher power consumption for blowing the gas flow through the moving bed. The pressure drop would depend on the gas flow to be conditioned and the particle size of the bed. Thus, particle bed sizes above $400 \mu \mathrm{m}$ should be recommended.

The MBHEF proposed here can be used as valuable and useful equipment for conditioning syngas to be fuelled in engine applications, saving operational costs in comparison with traditional cold syngas conditioning device. Further secondary treatment should be applied to improve the tar content removal if needed.

Additionally, using the same particle bed size that the one employed in BGFB reactors, the solid flow stream leaving the MBHEF could be recirculated to the BGFB reactor. This would avoid extra waste disposal problems and costs.

Finally, the modelling approach presented here can be a useful tool for studying 3D cases. This would help to gain accuracy and energy, exergy and economic optimization of the moving bed performance. The 3D modelling approach would also help to find possible scale-up effects when applying this method in industry.

\section{Acknowledgements}

The financial support from projects DPI2009-10518 (MICINN) and CARDENER-CM (S2009ENE-1660) is very much acknowledged.

\section{Notation}

a interfacial area, $\left[\mathrm{m}^{2} / \mathrm{m}^{3}\right]$

$a_{\mathrm{p}} \quad$ surface-volume particle ratio, $\left[\mathrm{m}^{2} / \mathrm{m}^{3}\right]$

$C_{\mathrm{c}} \quad$ concentration of specie " $\mathrm{c}$ " in gas phase in MBHEF, $\left[\mathrm{kg} / \mathrm{m}^{3}\right]$

$C_{\mathrm{p}, \mathrm{g}} \quad$ dust concentration in gas phase in MBHEF, $\left[\mathrm{kg} / \mathrm{m}^{3}\right]$

$C_{\mathrm{p}, \mathrm{p}} \quad$ dust concentration in solid phase in MBHEF, $\left[\mathrm{kg} / \mathrm{m}^{3}\right]$
$C_{c, p} \quad$ concentration of specie "c" in solid phase in MBHEF, $\left[\mathrm{kg} / \mathrm{m}^{3}\right]$

$C_{\mathrm{tar}}$ tar concentration in gas phase in MBHEF, $\left[\mathrm{mg} / \mathrm{m}^{3} \mathrm{n}\right]$

$c_{\mathrm{p}} \quad$ heat capacity, [J/kg K]

$D$ diffusivity of species in a multicomponent mixture of species, $\left[\mathrm{m}^{2} / \mathrm{s}\right]$

$d_{\mathrm{p}} \quad$ particle diameter, [m]

$G \quad$ generation term, $\left[\mathrm{kg} / \mathrm{m}^{3} \mathrm{~s}\right]$

$h \quad$ heat transfer coefficient by convection, $\left[\mathrm{W} / \mathrm{m}^{2} \mathrm{~K}\right]$

$h_{\mathrm{fg}, \mathrm{c}} \quad$ latent heat of component "c", [J/kg]

$k$ thermal conductivity, [W/m K]

$k_{\mathrm{m}} \quad$ fluid-particle mass transfer coefficient of component "m", [m/s]

$H \quad$ width of MBHEF, [m]

$L \quad$ length of MBHEF, [m]

$\dot{m} \quad$ condensation rate of component " $\mathrm{c}$ ", $\left[\mathrm{kg} / \mathrm{m}^{3} \mathrm{~s}\right]$

$n \quad$ number of chemical species/components

$\mathrm{nc}$ number of condensable components

$\mathrm{nr} \quad$ number of reactions

$P \quad$ coefficient of polynomic fitting for predicting tar dew point $[-]$

Q volume flow, $\left[\mathrm{m}^{3} / \mathrm{s}\right]$

$q_{\mathrm{rad}} \quad$ radiation heat loss $\left[\mathrm{W} / \mathrm{m}^{3}\right]$

$T \quad$ fluid temperature, [K]

$T_{\mathrm{dp}, \mathrm{tar}} \quad$ tar dew point, $[\mathrm{K}]$

$u_{\mathrm{g}}, v_{\mathrm{g}}, w_{\mathrm{g}}$ gas velocity components, [m/s]

$u_{\mathrm{l}}, v_{\mathrm{l}}, w_{\mathrm{l}}$ liquid velocity components, $[\mathrm{m} / \mathrm{s}]$

$u_{\mathrm{p}}, v_{\mathrm{p}}, w_{\mathrm{p}}$ solid velocity components, [m/s]

$U_{\mathrm{w}} \quad$ overall phase to surroundings heat transfer coefficient, $\left[\mathrm{W} / \mathrm{m}^{2} \mathrm{~K}\right]$

$x, y, z \quad$ spatial coordinates, [m]

$W_{\text {pump }}$ power pumping of fluid, [J/s]

$\begin{array}{ll}\text { Abbreviations } \\ \text { BFB } & \text { Bubbling Fluidized Bed } \\ \text { CFB } & \text { Circulating Fluidized Bed } \\ \text { EF } & \text { Entrained Flow } \\ \text { FBD } & \text { Fixed Bed Downdraft } \\ \text { FBU } & \text { Fixed bed Updraft } \\ \text { GHG } & \text { Greenhouse Gases } \\ \text { GT } & \text { Gas Turbine } \\ \text { ICE } & \text { Internal Combustion Engine } \\ \text { MBHEF } & \text { Moving Bed Heat Exchanger Filter } \\ \text { PA } & \text { Polycyclic Aromatic Hydrocarbons } \\ \text { syngas } & \text { synthesis gas }\end{array}$

Greek letters

$\Delta H_{\mathrm{r}} \quad$ reaction enthalpy or reaction " $\mathrm{r}$ ", $[\mathrm{J} / \mathrm{kg}]$

$\Delta P \quad$ pressure drop, [Pa]

$\varepsilon \quad$ phase fraction, porosity of bed inert material, [-]

$\eta \quad$ removal efficiency of tars/dust, [\%]

$\theta \quad$ solid phase temperature, [K]

$\lambda \quad$ filter coefficient $\left[\mathrm{m}^{-1}\right]$, mean free path of the gas molecules, $[\mu \mathrm{m}]$

$\mu \quad$ viscosity, $[\mathrm{kg} / \mathrm{m} \mathrm{s}]$

$\rho \quad$ density, $\left[\mathrm{kg} / \mathrm{m}^{3}\right]$

\section{Subscripts}

0 value of variable at the MBHEF inlet

a first chemical specie in a binary system of components

b second chemical specie in a binary system of components

c arbitrary chemical specie

cond condensate 
dust fine particles content/concentration. Fine particles. Fines

e effective

evap evaporate

f fluid

g gas phase

l liquid phase

M component or chemical specie

p particle, solid phase

r reaction arbitrary

s value of variable at the MBHEF outlet

tars tars content/concentration. Tars

$\infty \quad$ surroundings

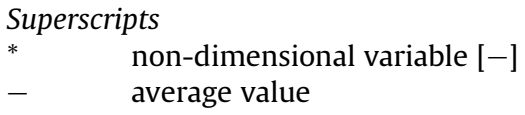

\section{Appendix}

The coefficients NTU*, CNTU* and STe* are dimensionless while $\mathrm{CPG}^{*}$ and $\mathrm{CPS}^{*}$ have units of energy $(\mathrm{J})$ per unit of volume $\left(\mathrm{m}^{3}\right)$ and time (s), and are defined as:

$$
\mathrm{CNTU}_{x+\Delta x}^{*}=\frac{h a_{\mathrm{e}} \Delta x^{*} \Delta y^{*} H}{\left.m_{\mathrm{g}} c_{\mathrm{pg}, x+\Delta x}+\sum_{c=1}^{n c} m_{\mathrm{gc}, x+\Delta x} c_{\mathrm{pgc}, x+\Delta x}\right) /(\mathrm{LHH})}
$$

$$
\begin{aligned}
& \mathrm{NTU}_{x+\Delta x}^{*}=\frac{m_{\mathrm{g}} c_{\mathrm{pg}, x+\Delta x}+\sum_{c=1}^{n c} m_{\mathrm{gc}, x+\Delta x} c_{\mathrm{pgc}, x+\Delta x}}{m_{\mathrm{p}} c_{\mathrm{pp}}+\sum_{c=1}^{n c} m_{\mathrm{pc}, y+\Delta y} c_{\mathrm{plc}, y+\Delta y}} \\
& \mathrm{ST}_{x+\Delta x}^{*}=\frac{m_{\mathrm{g}} c_{\mathrm{pg}, x+\Delta x}+\sum_{c=1}^{n c} m_{\mathrm{g} c, x+\Delta x} c_{\mathrm{pg} c, x+\Delta x}}{\sum_{c=1}^{n c} \dot{m}_{c} h_{\mathrm{f}, \mathrm{g} c}}\left(T_{0}^{*}-\theta_{0}^{*}\right)
\end{aligned}
$$

$C P G_{x}^{*}=\frac{m_{\mathrm{g}} c_{\mathrm{pg}, x}+\sum_{c=1}^{n c} m_{\mathrm{g} c, x} c_{\mathrm{pg} c, x}}{\mathrm{LHH}}$

$C P S_{y}^{*}=\frac{m_{\mathrm{p}} c_{\mathrm{pp}}+\sum_{c=1}^{n c} m_{\mathrm{p} c, y} c_{\mathrm{pl} c, y}}{\mathrm{LHH}}$

Concerning the definition of the dimensionless variables of interest in the MBHEF performance analysis, the non-dimension gas and solid temperatures and water, tars and dust concentration are expressed as follows:

$$
\begin{aligned}
& T_{x}^{*}=\frac{T_{x}-\theta_{0}}{T_{0}-\theta_{0}} \\
& \theta_{y}^{*}=\frac{\theta_{y}-\theta_{0}}{T_{0}-\theta_{0}} \\
& C_{\mathrm{g}, x}^{*}=\frac{C_{\mathrm{g}, x}-C_{\mathrm{s}, 0}}{C_{\mathrm{g}, 0}-C_{\mathrm{s}, 0}} \\
& C_{\mathrm{s}, y}^{*}=\frac{C_{\mathrm{s}, y}-C_{\mathrm{s}, 0}}{C_{\mathrm{g}, 0}-C_{\mathrm{s}, 0}} \\
& C_{\mathrm{pg}, x}^{*}=\frac{C_{\mathrm{pg}, x}-C_{\mathrm{pp}, 0}}{C_{\mathrm{pg}, 0}-C_{\mathrm{pp}, 0}}
\end{aligned}
$$

$C_{\mathrm{pp}, y}^{*}=\frac{C_{\mathrm{pp}, y}-C_{\mathrm{pp}, 0}}{C_{\mathrm{pg}, 0}-C_{\mathrm{pp}, 0}}$

\section{References}

[1] H.J. Herzog, Scaling up carbon dioxide capture and storage: from megatons to gigatons, Energy Econ. 33 (4) (2011) 597-604.

[2] P. McKendry, Energy production from biomass (part 3): gasification technologies, Bioresour. Technol. 83 (1) (2002) 55-63.

[3] N.L. Panwar, S.C. Kaushik, S. Kothari, Role of renewable energy sources in environmental protection: a review, Renew. Sustain. Energy Rev. 15 (3) (2011) 1513-1524.

[4] L. Shi, M.Y.L. Chew, A review on sustainable design of renewable energy systems, Renew. Sustain. Energy Rev. 16 (2012) 192-207.

[5] A. Angelis-Dimakis, M. Biberacher, J. Domínguez, G. Fiorese, S. Gadocha, E. Gnansounou, G. Guariso, A. Kartalidis, L. Panichelli, I. Pinedo, M. Robba, Methods and tools to evaluate the availability of renewable energy sources, Renew. Sustain. Energy Rev. 15 (2) (2011) 1182-1200.

[6] H. Herzog, E. Drake, E. Adams, $\mathrm{CO}_{2}$ Capture, Reuse and Storage Technologies for Mitigating Global Climate Change, Massachusetts Institute of Technology, MA, USA, 1997. DOE No DE-AF22-96PC01257.

[7] H. Herzog, D. Golomb, Carbon capture and storage from fossil fuel use, in: Encyclopedia of Energy, Massachusetts Institute of Technology, MA, USA, 2004.

[8] K.J. Ptasinski, Thermodynamic efficiency of biomass gasification and biofuels conversion, Biofuels Bioprod. Biorefin. 2 (3) (2008) 239-253.

[9] T.A. Milne, R.J. Evans, Biomass Gasifier "tars": Their Nature, Formation and Conversion, National Renewable Energy Laboratory, NREL, Golden, CO, USA, 1998. Report no. NREL/TP-570-25357.

[10] C. Li, K. Suzuki, Tar property, analysis, reforming mechanism and model for biomass gasification. An overview, Renew. Sustain. Energy Rev. 13 (3) (2009) 594-604.

[11] A. Gómez-Barea, B. Leckner, A. Villanueva-Perales, S. Nilsson, D. Fuentes-Cano, Improving the performance of fluidized bed biomass/waste gasifiers for distributed electricity: a new three-stage gasification system, Appl. Therm. Eng. 50 (2) (2012) 1453-1462.

[12] R.W.R. Zwart, Gas Cleaning Downstream Biomass Gasification, Energy Research Centre of Netherlands, ECN, Petten, The Netherlands, 2009. Status Report. ECN-E-08-078

[13] J.R. Longanbach, Preparing advanced coal-based power systems for the 21st century at the power systems development facility in Wilsonville, Alabama, in: Proc. 23rd Int. Technical Conf. on Coal Utilization and Fuel Systems, Clearwater, FL, USA, 1998, pp. 69-78.

[14] J. Smid, S.S. Hsiau, C.Y. Peng, H.T. Lee, Moving bed filters for hot gas cleanup, Filtr. Sep. 42 (6) (2005a) 34-37.

[15] A. Soria-Verdugo, J.A. Almendros-Ibáñez, U. Ruiz-Rivas, D. Santana, Exergy optimisation in a steady moving bed heat exchanger, Ann. N.Y. Acad. Sci. 1161 (2009) 584-600.

[16] P. Hasler, T. Nussbaumer, Gas cleaning for IC engine applications from fixed bed biomass gasification, Biomass Bioenergy 16 (6) (1999) 385-395.

[17] H.E.M. Stassen, Strategies for upgrading producer gas from fixed bed gasifie systems to internal combustion engine quality, in: R.G. Graham, R. Bain (Eds.) Biomass Gasification: Hot-gas Clean-up, IEA Biomass Gasification Working Group, 1993, pp. 33-44.

[18] L.P.L.M. Rabu, D. Jansen, De-centralised Power Production Using Low-calorific Value Gas from Renewable Energy Resource in Gas Turbines, Energy Research Centre of Netherlands, ECN, Petten, The Netherlands, 2001.

[19] A. Gómez-Barea, B. Leckner, Gasification of biomass and waste, in: M. Lackner F. Winter, A.K. Agarwal (Eds.), Handbook of Combustion, vol. 4, Wiley-VCH, Weinheim, 2009, pp. 365-397.

[20] H. Thunman, F. Niklasson, F. Johnsson, B. Leckner, Composition of volatiles gases and thermochemical properties of wood for modelling of fixed or fluidized beds, Energy Fuels 15 (6) (2001) 1488-1497.

[21] J.H.A. Kiel, S.V.B. van Paasen, J.P.A. Neeft, L. Devi, K.J. Ptasinski, F.J.J.G. Janssen, Primary Measures to Reduce Tar Formation in Fluidized-bed Biomass Gasifiers. Final Report SDE project P1999-12, Energy Research Centre of the Netherlands, ECN, The Netherlands, 2004. Report ECN-C-04-014.

[22] L. Devi, K.J. Ptasinski, F.J.J.G. Janssen, A review of the primary measures for tar elimination in biomass gasification processes, Biomass Bioenergy 24 (2) (2003) 125-140.

[23] J. Corella, J.M. Toledo, G. Molina, Calculation of the conditions to get less than $2 \mathrm{~g} \mathrm{tar} / \mathrm{m}_{\mathrm{n}}$ in a fluidized bed biomass gasifier, Fuel Process. Technol. 87 (9) (2006) 841-846.

[24] P. Weerachanchai, M. Horio, C. Tangsathitkulchai, Effects of gasifying conditions and bed materials on fluidized bed steam gasification of wood biomass, Bioresour. Technol. 100 (3) (2009) 1419-1427.

[25] S. Kaewluan, Pipatmanomai, Gasification of high moisture rubber woodchip with rubber waste in a bubbling fluidized bed, Fuel Process. Technol. 92 (3) (2011) 671-677.

[26] G. Ruoppolo, F. Miccio, B. Piriou, R. Chirone, Biomass gasification in a catalytic fluidized reactor with beds of different materials, Chem. Eng. J. 154 (1-3) (2009) 369-374. 
[27] M. Detournay, M. Hemati, R. Andreux, Biomass steam gasification in fluidized bed of inert or catalytic particles: comparison between experimental results and thermodynamic equilibrium predictions, Powder Technol. 208 (2) (2011) 558-567.

[28] B. Dou, W. Pan, J. Ren, B. Chen, J. Hwang, Y. Tae-U, Removal of tar component over cracking catalysts from high temperature fuel gas, Energy Convers. Manage. 49 (8) (2008) 2247-2253.

[29] U. Arena, L. Zaccariello, M.L. Mastellone, Tar removal during the fluidized bed gasification of plastic waste, Waste Manage. 29 (2) (2009) 783-791.

[30] S. Schmidt, S. Giesa, A. Drochner, H. Vogel, Catalytic tar removal from bio syngas-Catalyst development and kinetic studies, Catal. Today 175 (1) (2011) $442-449$.

[31] A. Lozano, V. Henriquez, A. Macias-Machín, Modelling of a new crossflow moving-bed heat-exchanger/filter (MHEF), Filtr. Sep. 33 (1) (1996) 69-74.

[32] V. Henriquez, A. Macías-Machín, Hot gas filtration using a moving bed heat exchanger-filter (MHEF), Chem. Eng. Process. 36 (5) (1997) 353-361.

[33] J. Smid, S.S. Hsiau, C.Y. Peng, H.T. Lee, Granular moving bed filters and adsorbers/GM-BF/A) - patent review: 1970-2000, Adv. Powder Technol. 16 (4) (2005b) 301-345.

[34] M. Socorro, A. Macías-Machín, J.M. Verona, D. Santana, Hot gas filtration and heat exchange in a packed bed using lapilli as a granular medium, Ind. Eng. Chem. Res. 45 (23) (2006) 7957-7966.

[35] T. Hu, A.H. Hassabou, M. Spinnler, W. Polifke, Performance analysis and optimisation of direct contact condensation in a PCM fixed bed regenerator, Desalination $280(1-3)(2011) 232-243$.

[36] J.A. Almendros-Ibáñez, A. Soria-Verdugo, U. Ruiz-Rivas, D. Santana, Solid conduction effects and design criteria in moving bed exchangers, Appl. Therm. Eng. 31 (6-7) (2011) 1200-1207.

[37] B.R. Bird, W.E. Stewart, E.N. Lightfoot, Transport Phenomena, second ed., Wiley, New York, USA, 2002
[38] E.N. Fuller, P.D. Schettler, J.C. Giddings, A new method for prediction of binary gas-phase diffusion coefficients, Ind. Eng. Chem. 58 (5) (1966) 19-27.

[39] C.R. Wilke, Diffusional properties of multicomponent gases, Chem. Eng. Prog. 46 (2) (1950) 95-104.

[40] JANAF Database (therm.dat) from CHEMKIN File therm.dat v4.0, March, 2004 users.rowan.edu/ marchese/combustion04/kinetics/h2-chemkin/therm.dat.

[41] R.E. Thek, L.I. Stiel, A new reduced vapor pressure equation, AIChE J. 12 (3) (1966) 599-602.

[42] E. Achenbach, Heat and flow characteristics of packed beds, Exp. Therm. Fluid Sci. 10 (1) (1995) 17-27.

[43] W.E. Ranz, Friction and transfer coefficients for single particles and packed beds, Chem. Eng. Prog. 48 (5) (1952) 247-253.

[44] P. Gandhidasan, Estimation of the effective interfacial area in packed-bed liquid desiccant contactors, Ind. Eng. Chem. Res. 42 (12) (2003) 3420-3425.

[45] M. Campoy-Naranjo, Biomass and Wastes Gasification in Fluidised Bed: Pilot Plant Studies (PhD Thesis), University of Sevilla, Spain, 2009 (in Spanish).

[46] C. Tien, Principles of Filtration, first ed., 2012. Oxford, UK.

[47] M. Campoy, A. Gómez-Barea, F.B. Vidal, P. Ollero, Air-steam gasification of biomass in a fluidised bed: process optimisation by enriched air, Fuel Process. Technol. 90 (5) (2009) 677-685.

[48] A. Gómez-Barea, B. Leckner, Modeling of biomass gasification in fluidized bed, Prog. Energy Combust. Sci. 36 (4) (2010) 444-509.

[49] J.C. Ginestra, R. Jackson, Pinning of a bed of particles in a vertical channel by a crossflow of gas, Ind. Eng. Chem. Fund. 24 (2) (1985) 121-128.

[50] S. Ergun, Fluid flow through packed columns, Chem. Eng. Process. 48 (2) (1952) 89-94.

[51] P. Hasler, T. Nussbaumer, R. Buehler, Evaluation of Gas Cleaning Technologies for Small Scale Biomass Gasifiers, Swiss Federal Office of Energy, Berne, Switzerland, 1997 